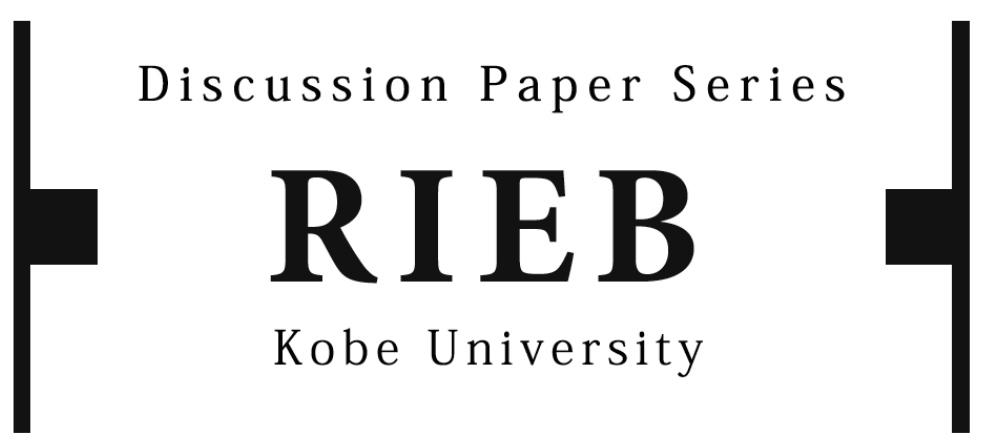

DP2017-05

\title{
Identifying Unconventional Monetary Policy Shocks
}

Kiyotaka NAKASHIMA

Masahiko SHIBAMOTO

Koji TAKAHASHI

Revised April 26, 2017

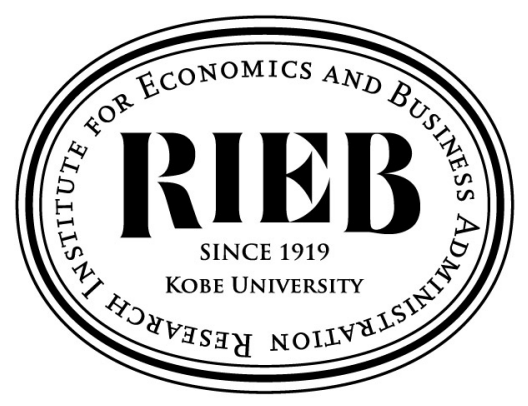

Research Institute for Economics and Business Administration Kobe University 


\title{
IDENTIFYING UNCONVENTIONAL MONETARY
}

\section{POLICY SHOCKS*}

\author{
Kiyotaka NAKASHIMA ${ }^{\dagger}$ \\ Masahiko SHIBAMOTO $\ddagger$ \\ Konan University \\ Kobe University \\ Koji TAKAHASHI $\S$ \\ University of California, San Diego
}

April 26, 2017

${ }^{*}$ We are grateful for the helpful comments and discussions by Kosuke Aoki, James D. Hamilton, Yuzo Honda, Takeo Hoshi, Ryo Jinnai, Junko Koeda, Kenneth N. Kuttner, Ryuzo Miyao, Yasutomo Murasawa, Etsuro Shioji, Minoru Tachibana, Takeru Terao, Yoshiro Tsutsui, seminar participants at Hitotsubashi University, Konan University, and Kobe University, and conference participants at 2016 Japanese Economic Association Autumn Meeting at Waseda University. We would also like to thank Miho Kohsaka for providing excellent research assistance. This study received financial support in the form of a Grants-in-Aid from the Japanese Ministry of Education and Science.

$\dagger$ Kiyotaka Nakashima, Faculty of Economics, Konan University, Okamoto 8-9-1, Higashinada, Kobe, 658-8501, Japan, e-mail: kiyotaka@center.konan-u.ac.jp.

$\ddagger$ Correspondence to: Masahiko Shibamoto, Research Institute for Economics and Business Administration, Kobe University, 2-1, Rokkodai, Nada, Kobe, 657-8501, Japan, e-mail: shibamoto@rieb.kobe-u.ac.jp.

$\S$ Koji Takahashi, Department of Economics, University of California, San Diego, 9500 Gilman Dr., La Jolla, CA, 92093-0508, United States of America, e-mail: ktakahas@ucsd.edu 


\begin{abstract}
This paper proposes a novel method for identifying unconventional monetary policy shocks. The method incorporates the movement of two unconventional monetary policy indicators, namely, the size and composition of the central bank's balance sheet, after the bank makes policy decisions. Under some restrictions imposed in the vector autoregressive model, we identify two unconventional policy shocks, quantitative and qualitative shocks, as news shocks that best portend the current and future paths of the unconventional policy indicators in response to the policy shocks. The qualitative easing shocks have expansionary effects on the real economy, while the quantitative easing shocks have contractionary effects.
\end{abstract}

JEL Classification: E52, E58.

Keywords: quantitative easing; qualitative easing; conventional monetary policy; vector autoregressive model; news shock 


\section{Introduction}

Central banks have several monetary policy options, even under the interest rate lower bound (Bernanke and Reinhart (2004)). Since February 1999, for example, the Bank of Japan (BOJ) has newly developed its so-called unconventional monetary policy. By setting the targeted overnight call rate (OCR) to almost $0 \%$, the BOJ adopted a quantitative easing policy in March 2001. Under this policy framework, the monetary base (MB), or size of the BOJ's balance sheet, expanded at an OCR of $0 \%$ through the growth of excess reserves in the BOJ's current account bases (see Figure 1). The quantitative easing policy ended in March 2006. The targeted rate, however, has remained well below $0.5 \%$ since then. In its quantitative and qualitative easing policy introduced in April 2013, the BOJ further deepened its unconventional policy framework not simply by enlarging its balance sheet, but by increasing the ratio of unconventional assets on the balance sheet. ${ }^{1}$ Central banks in industrialized countries such as the United States, the United Kingdom, and the Euro area have followed with their own unconventional policy frameworks similarly characterized by increases in the sizes of central bank balance sheets and changes in the balance sheet compositions at extremely low policy-targeted interest rates.

Although the actual implementation of the unconventional monetary policy in many countries has stimulated empirical research on unconventional policy effects using the structural vector autoregressive (VAR) model, the policy effects on the real economy are still disputable. The difficulty in identifying exogenous unconventional policy shocks is particularly confounding in this respect. ${ }^{2}$ One of the biggest challenges in assessing unconventional policy effects by VAR analysis is the choice of variables to use as monetary policy indicators precisely reflecting the central bank's policy decisions in the unconventional monetary policy. More simply, how should we associate the monetary policy indicators with the exogenous components of the unconventional monetary policy? A number of previous studies have assumed that

\footnotetext{
${ }^{1}$ See Shiratsuka (2010) and Ueda (2012) for a detailed explanation of unconventional assets in Japan.

${ }^{2}$ See Joyce et al. (2012) for a survey of the empirical research on unconventional policy effects.
} 
monetary aggregates such as the MB and excess reserves represent the central bank's policy stance, thus utilizing their reduced-form VAR innovations as exogenous components of the unconventional monetary policy (Iwata and Wu (2006), Inoue and Okimoto (2008), Honda et al. (2013), Hayashi and Koeda (2014), and Kimura and Nakajima (2016)). This empirical strategy is essentially an extension of the standard recursive VAR approach to estimate the effects of the conventional monetary policy in which central banks control short-term nominal interest rates (Bernanke and Blinder (1992) and Christiano et al. (1996)). The other strand of empirical research for unconventional policy effects has employed a strategy requiring no extraction of exogenous policy components from the central bank's policy indicators. By assuming that unconventional monetary policy shocks can be represented collectively as a single unobservable policy shock, they impose restrictions on the impulse responses of the macroeconomic variables to the single monetary policy shock (Kapetanios et al. (2012), Baumeister and Benati (2013), and Gambacorta et al. (2014)) and on a variance-covariance matrix of structural shocks including a single policy shock (Wright (2012) and Rogers et al. (2014)).

We also know, however, that central banks control for policy variables in tandem in a low interest rate environment. As long as they do so, the two aforesaid empirical strategies are insufficient to assess the different effects of unconventional policy tools. In the case of Japan, the BOJ has purchased a vast range of different financial assets such as exchange trade funds, commercial papers, and long-term government bonds. To investigate whether different policy instruments have different effects on the real economy, we assume that the monetary policy implemented by the BOJ in a low interest rate environment has been arranged in three dimensions: a quantitative easing setting, qualitative easing setting, and conventional policy rate setting.

In this paper we introduce a novel identification approach to disentangle the causal effects of the BOJ's three policy shocks on macroeconomic variables. To this end, we first show how the monetary policy indicators respond to the BOJ's policy decisions on a number of specific monetary policy meeting (MPM) days. Then we propose a new strategy for coping with 
the issues entailed in identifying unconventional monetary policy shocks by focusing on three issues: the variation of policy tools, the endogeneity of the monetary policy indicators, and unconventional policy shocks as news shocks. ${ }^{3}$

Following the previous literature, we employ a straightforward approach to pin down the timing when monetary policy shocks arise in the economy (Kuttner (2001), Cochrane and Piazzesi (2002), Gürkaynak et al. (2005a,b), Honda and Kuroki (2006), Gürkaynak et al. (2007) and Campbell et al. (2012)). The BOJ decides its policy scheme at MPMs (previously, the meetings were held once or twice a month) and publicly states its policy decision just after each meeting. As the public statement after the MPM is the BOJ's main communication tool, we exploit the idea that monetary policy shocks are reflected in the changes of asset prices just after the statement. In other words, we take up the market responses to the BOJ's policy decision statements, that is, the monetary policy surprises in financial markets or the revised expectations of market participants embedded in financial asset valuations, as monetary policy shocks. As long as we correctly characterize the monetary policy surprises, we can use them as the instrumental variables of the reduced-form VAR innovations to identify the causal effects of the BOJ's monetary policy shocks on macroeconomic variables. ${ }^{4}$

Another identifying issue is how monetary policy indicators respond to policy changes. As discussed above, previous studies on unconventional policy effects based on VAR analysis have taken either of two approaches. Some have assumed the reduced-form VAR innovations of monetary aggregates such as the MB to be unconventional policy shocks. Others have imposed restrictions on the impulse responses of some of the variables to a single unobserved unconventional policy shock. Irrespective of the difference in methodology, both of these approaches make the common assumption that all monetary policy shocks to monetary aggregates are unanticipated, and that unconventional policy shocks yield favorable

\footnotetext{
${ }^{3}$ Note that our strategy cannot distinguish anticipated shocks from unanticipated ones. While previous studies using a VAR model often interpret all shocks as unanticipated, either intentionally or unintentionally, we incorporate anticipated shocks into our model together with unanticipated shocks.

${ }^{4}$ See Stock and Watson (2012) for a detailed survey of this empirical strategy for identifying U.S. monetary policy shocks using monetary policy surprises, namely, changes in asset market prices on Federal Fund Open Market Committee dates.
} 
effects on the macroeconomy. Their identification, however, is implausible in terms of the dynamics of the unconventional and conventional policy indicators. More specifically, the size and composition of a central bank's balance sheet do not reflect the policy changes of the central bank immediately after an announcement, whereas the bank's policy rate does. As the BOJ clarifies in its statement, the target levels of unconventional policy instruments are basically achieved after several months or a year has passed from the BOJ's policy change announcement. Hence, agents in the economy can anticipate large changes in monetary policy indicators, including the monetary base, even in the long-run future. But if we impose a simple restriction on a VAR model such as a recursive restriction and ignore the difference between those unconventional policy indicators and the OCR, we may misspecify those anticipated changes as unanticipated shocks.

Premising that anticipated unconventional monetary policy shocks are mainly attributable to the actual movements of observable unconventional policy indicators, we identify two unconventional monetary policy shocks relating to the size and composition of the BOJ's balance sheet as news shocks that best presage their current and future paths. ${ }^{5}$ To identify the unconventional shocks, we also impose that those shocks do not affect the contemporaneous changes in the OCRs. We also identify one conventional monetary policy shock as a shock that has an instantaneous impact on the BOJ's policy rate. These identifying restrictions reveal that central banks seek to gradually achieve their target levels for the unconventional policy measures after policy decisions and implement unconventional monetary policy when they cannot pursue the conventional policy option of lowering short-term nominal interest rates (Bernanke and Reinhart (2004)).

By identifying quantitative, qualitative, and conventional policy shocks, we provide evidence that the quantitative easing shock, the shock that increases the size of the BOJ's balance sheet, significantly decreases the long-term nominal interest rate without conferring any favorable effects on real economic activity. On the contrary, the qualitative easing and

\footnotetext{
${ }^{5}$ Milani and Treadwell (2012) tried to disentangle the anticipated and unanticipated components of policy shocks by constructing a New Keynesian model that incorporates news about future policy rates.
} 
conventional policy shocks, the shocks that respectively increase the BOJ's unconventional asset ratio to its total assets and immediately decrease the policy rate, bring about expansionary effects.

The remainder of this paper is organized as follows. Section 2 analyzes the movement in each policy indicator in response to the BOJ's actual policy changes and our monetary policy surprise measures. Section 3 proposes an identification method considering different effects of the aforesaid three policy shocks on the economy. Section 4 reports the estimation results for the monetary policy shocks and explores several implications given our empirical findings. Section 5 closes the paper with concluding comments. The Appendix provides a detailed description of the procedure we used to construct the monetary policy surprises.

\section{Monetary Policy Changes and Monetary Policy In- dicators}

In this section we examine the movements of monetary policy indicators in response to policy changes. By doing so, we show the need for our method of using the structural VAR approach to identify monetary policy shocks relating to each of three policy indicators, one conventional and two unconventional. The conventional policy indicator is the OCR. The unconventional policy indicators are the MB and the composition ratio of the BOJ's unconventional assets to its total assets (termed "COMP" hereafter). Within the framework of the BOJ's unconventional monetary policy, the MB, or the size of the BOJ's balance sheet, is a quantitative policy indicator, and the composition ratio is a qualitative policy indicator (Shiratsuka (2010) and Ueda (2012)).

\section{$2.1 \quad$ Event Study Illustration}

In this subsection we conduct an event study analysis of the response of the policy indicators to the introduction of the new monetary policy schemes. The aim here is to illustrate more 
concretely the degree of variation in the response of the monetary policy indicators to actual policy changes and the importance of introducing a structural analysis. Figures 2 to 5 show the time path of the MB, COMP, and OCR during the following four periods: 1) the introduction of the zero interest rate policy in February 1999, 2) the end of the zero interest rate policy in August 2000 and introduction of quantitative easing in March 2001, 3) the end of quantitative easing in March 2006 and return of the conventional monetary policy through short-term interest rate control in July 2006, and 4) the introduction of the quantitative and qualitative easing policy in April 2013.

A common pattern can be observed in all of the figures: the short-term interest rate (OCR) responded to the BOJ's monetary policy immediately upon the entry of the new regimes, while the $\mathrm{MB}$ and $\mathrm{COMP}$, the quantitative and qualitative indicators, responded more continuously and gradually. If we look at the period following the introduction of the zero interest rate policy in 1999 (Figure 2), for example, we see that the OCR decreased immediately in response to the policy change, whereas the MB and COMP showed only small immediate responses but then continuously rose thereafter. ${ }^{6}$ This event study shows how the unconventional indicators move slowly and later in time in response to policy changes, while the policy rate moves immediately.

The ending of the zero interest rate policy in 2000 and the introduction of quantitative easing in 2001 (Figure 3) quickly raised and lowered the policy rate, respectively. Among the unconventional policy indicators, the COMP responded to the end of the zero interest rate policy and introduction of quantitative easing by immediately and continuously decreasing and increasing. On the contrary, the MB showed no immediate change following these policy changes. These responses of the unconventional policy indicators following the introduction of quantitative easing in March 2001 show that the BOJ began purchasing long-term government

\footnotetext{
${ }^{6}$ Under the conventional monetary policy framework, the COMP decreases because central banks purchase conventional assets to lower short-term nominal interest rates. From the estimated increase in the COMP following the decrease in the OCR, we can infer that the BOJ purchased unconventional assets with sufficient aggressiveness to induce the COMP to rise in the unconventional monetary policy framework after the introduction of the zero interest rate policy.
} 
bonds as an unconventional asset, as the MB had already met its target level. From August to December 2001, however, the BOJ expanded quantitative easing by continuously increasing the MB and consistently lowering the OCR. In this period, the BOJ thus implemented the unconventional monetary policy through quantitative easing.

Note also that, as shown in Figures 2 and 3, the introduction and end of the zero interest rate policy in 1999 and 2000 yielded different associations between the responses of the three policy indicators. This finding suggests that the policy rate changes were associated with the different unconventional policy operations of the MB and COMP. Here, therefore, we go on to separately identify each policy shock involving the OCR, MB, and COMP.

As reported in Figure 4, the end of quantitative easing in March 2006 led to a continuous decrease in the MB and increase in the COMP, thereby serving as a quantitative tightening and qualitative easing policy. By contrast, the OCR remained unchanged in response to the policy change, as the BOJ maintained the zero interest rate policy in spite of its decision to end quantitative easing. These results tell us that even as the BOJ lifted the quantitative easing, leaving the policy rate in the zero lower bound, it conducted the unconventional monetary policy by controlling the MB and COMP (i.e., the targeted variables). We should also note that the OCR immediately rose following the recurrence of short-term interest rate controls in July 2006. The MB decreased slightly in this month, whereas the COMP decreased drastically. When the BOJ raised the target rate for the OCR in February 2007, the OCR and the COMP both rose while the MB remained unchanged. Hence, the periods of June 2006 and February 2007 were characterized by policy tightening in terms of the conventional monetary policy framework, and policy tightening and easing in terms of the unconventional qualitative policy framework.

While we see, from Figure 5, that the quantitative and qualitative easing policy introduced in 2013 was followed by continuous and gradual increases of the MB and COMP, it had almost no effect on the OCR. This was a consequence of the short-term interest rate, which had remained substantially in the zero lower bound since December 2008, when the BOJ 
lowered its target rate for the OCR from $0.3 \%$ to $0.1 \%$.

Given the above event study analysis, we provide two insights to identify the monetary policy shocks delivered in the unconventional monetary policy regime. First, the responses of the three policy indicators have no particular relationship; that is, we find no simple associations among their responses to similar types of policy changes such as changes in the policy rate or the size of the central bank's balance sheet. In the absence of such a relationship, we have no way of integrating monetary policy shocks in the unconventional monetary policy regime into a single policy shock. Put differently, we must separately identify the three monetary policy shocks corresponding to the monetary policy indicators.

Second, the unconventional policy indicators (MB and COMP) show no responses immediately following the monetary policy changes, whereas the short-term nominal interest rate (OCR) responds quickly and substantially. This difference in the responses of the policy indicators to the policy changes stems from differences in the indicators themselves. The unconventional policy indicators are essentially quantitative financial variables that reach their target levels later, after central banks state their policy changes for the sizes and compositions of their balance sheets. In this sense, unconventional policy shocks relating to the MB and COMP must be characterized as "anticipated shocks" or "news shocks" that portend the future paths of these two indicators. By contrast, the policy rate is essentially the market price of reserve deposits, a variable that reaches its target level quickly through an immediate reaction of the reserves market.

\subsection{Monetary Policy Surprises and Monetary Policy Indicators}

As we discussed earlier in the Introduction, the fundamental issue to consider in identifying monetary policy shocks in relation to policy indicators is the timing of the central bank's policy decision announcement. In this subsection we discuss the source from which monetary policy shocks originate.

The BOJ decides its policy scheme in an MPM held about twice per month and publicly 
states its policy decision just after the meeting closes. As such, we can assume that the BOJ's monetary policy shocks originate from revisions in the expectations of agents in the asset markets. This empirical strategy helps us overcome identification problems that arise with regard to endogenous responses of monetary policy when we simply treat innovations of monetary policy indicators as policy shocks in a monthly or quarterly VAR model. If we were to apply the innovations in such VAR models, the models would be contaminated by their endogenous responses to the underlying financial variables and other macroeconomic variables left out of the VAR system (Romer and Romer (2004), Faust et al. (2004), Gertler and Karadi (2015), and Shibamoto (2016)). ${ }^{7}$ Hence, as we go on to discuss in detail in the next section, we use monetary policy surprises in asset markets, or revisions in the expectations of agents in asset markets, as external instruments to control for the endogenous responses of the three monetary policy indicators to the variables remaining in and out of the VAR.

Previous studies constructed monetary policy surprises by focusing on changes in shortterm interest rate futures and using their high-frequency daily trading data. Kuttner (2001), Cochrane and Piazzesi (2002), Gürkaynak et al. (2005a,b), Gürkaynak et al. (2007), and Campbell et al. (2012) constructed monetary policy surprises in federal funds or Eurodollar futures occurring on Federal Open Market Committee dates. Honda and Kuroki (2006) constructed monetary policy surprises in euro-yen futures occurring on the BOJ's MPM dates from 1989 to 2001. Although these studies examined financial market responses to exogenous monetary policy shocks under the conventional policy regime, this empirical strategy is still useful for identifying the BOJ's monetary policy shocks under the unconventional policy regime. $^{8}$ We cannot, however, follow the strategy simply because short-term interest rate futures have hardly changed since the BOJ's introduction of its unconventional monetary policy. Here, therefore, we depart from previous studies by looking beyond changes in a

\footnotetext{
${ }^{7}$ Romer and Romer (2004), Faust et al. (2004), Gertler and Karadi (2015), and Shibamoto (2016) pointed out that the reduced-form VAR innovations of policy rates would have a substantial bias in identifying the monetary policy effect.

${ }^{8}$ Gagnon et al. (2011) and Swanson (2011) used an event study analysis to investigate monetary policy effects on an asset's market price in the United States. Joyce et al. (2011) and Ueda (2012) used an event study analysis to estimate financial market responses to monetary policy in the United Kingdom and Japan.
} 
particular asset market and exploiting all information on changes in the major financial markets just before and just after the BOJ's public statements. More concretely, we employ the principal component approach of Bernanke et al. (2004) and Gürkaynak et al. (2005b) and prepare for the monetary policy surprises as common factors of unanticipated changes in the major financial market variables following the public statements. ${ }^{9}$

We use twelve financial market variables to extract the monetary policy surprises as common factors: one futures rate (the three-month euro-yen TIBOR futures rate), five yen interest swap rates (the one-year, two-year, five-year, ten-year, and thirty-year yen interest swap rates), one short-term spot rate (the three-month euro-yen TIBOR rate), two spot exchange rates (the Yen-U.S. dollar spot exchange rate and the Yen-AUS dollar spot exchange rate in the Tokyo market), two stock price indexes (TOPIX and Nikkei Jasdaq index), and bank reserve deposits. Next, we compute the three common factors as monetary policy surprises on the twelve financial markets. The Appendix gives further details on the procedure we used to construct the three common factors.

Below we examine the statistical relevance among the monetary policy surprises and monetary policy indicators by running the following distributed lag regression of the policy indicators on the current and lagged monetary policy surprises: ${ }^{10}$

$$
y_{t}^{M P I}=r_{\iota, M P I, M P S}+\sum_{p c=1}^{3} \sum_{h=0}^{H} r_{M P I, p c}^{M P} M P S_{t-h}^{p c}+e_{t}^{M P I, M P S},
$$

where $y_{t}^{M P I}$ denotes each of the monetary policy indicators: OCR, MB, and COMP. For the MB, we examine not only its logarithmic value, but also its monthly growth rates of log-differenced values. $M P S_{t-h}^{p c}$ indicates the $h$ lagged values for the three monetary policy surprises generated using the factor analysis. $r_{\iota, M P I, M P S}$ and $e_{t}^{M P I, M P S}$ are constant terms

\footnotetext{
${ }^{9}$ Unlike this paper, Bernanke et al. (2004) and Gürkaynak et al. (2005b) aggregated information on shortterm futures with different maturities. We do not use the same type of information because, as discussed above, the nominal interest rates in short-term futures in Japan have stayed in the zero lower bound since the BOJ introduced the unconventional monetary policy.

${ }^{10}$ This regression corresponds to the first component $\left(\sum_{\tau=0}^{h} \Phi_{\tau} R^{M P} \xi_{t+h-\tau}^{M P}\right)$ of regression (9) introduced in subsection 3.3 .
} 
and stochastic disturbances, respectively.

Table 1 reports the estimation results for the distributed lag regression. As the table shows, the monetary policy surprises are statistically correlated with the monetary policy indicators. Specifically, we find that they are significantly associated with the OCR at the horizon of $h=0$, though most of our sample includes periods of $0 \%$ interest rates. This association tells us that monetary policy surprises have information on the movement in the BOJ's policy rate. By contrast, monetary policy surprises show no significant association with the MB or COMP at the horizon $h=0$, but are significantly associated with the MB $h \geq 12$ and with the COMP at $h \geq 2$. These estimation results imply that the MB and COMP respond to the BOJ's policy changes slowly and later in time.

Our finding on the responses of the unconventional monetary policy indicators clearly indicates that monetary policy surprises have substantial information on their future movements, but not on their contemporaneous ones. In other words, the public statements about changes in the two unconventional policy indicators released just after the MPM have the feature of a news shock that portends future changes in the indicators. In the next section we incorporate these medium- and long-term findings among the monetary policy surprises and two unconventional policy indicators into an identifying restriction on the intertemporal relations among the unconventional monetary policy shocks and indicators.

Note, also, that each of the monetary policy indicators has a differential association with the monetary policy surprises. These differential associations compel us to separately identify the three monetary policy shocks relating to the three policy indicators: one conventional monetary policy shock that aims to exogenously change short-term nominal interest rates and two unconventional monetary policy shocks that aim to exogenously change the size and composition of the central bank's balance sheet. 


\section{Identifying Monetary Policy Shocks under the Un- conventional Policy Regime}

This section describes the empirical strategy we use to identify the effects of the conventional and unconventional monetary policy shocks in the structural VAR analysis. First, we assume that monetary policy shocks originate from the public statements released just after the MPM. Second, we account for the identifying restrictions that incorporate the features of the monetary policy indicators discussed in Section 2. Specifically, we impose restrictions on the unconventional monetary policy shocks that turn out to capture current and future changes in the size and composition of the BOJ's balance sheet, while we define the conventional monetary policy shock as a shock that has an immediate impact on the central bank's policy rate, or the overnight call rate (OCR). In parallel, we assume that unconventional monetary policy shocks have no contemporaneous effects on the level of the OCR. This assumption reflects that the central bank tendency implements the unconventional monetary policy when conventional policy options (e.g., controlling the short-term interest rate) are no longer viable, as Bernanke et al. (2004) and others discussed.

Our procedure for VAR identification is based on the following two-step approach. In the first step, we use the monetary policy surprises as the instrumental variables of the reduced-form VAR innovations of the three policy indicators and other macroeconomic variables. Specifically, we construct an impact matrix for the instantaneous responses of the VAR variables by disentangling the causal relationships among the monetary policy shocks and VAR variables. The impact matrix in this stage disregards the movement in the unconventional policy indicators following policy changes. We therefore impose restrictions, in the second step, to identify the unconventional monetary policy shocks (i.e., the quantitative and qualitative shocks), which we define as shocks that best explain the revisions of an agent's expectations about the current and future paths of the size and composition of the central bank's balance sheet, but that have no contemporaneous effects on the OCR. To this end, we 
employ the maximum forecast error variance (MFEV) approach from Francis et al. (2014), which builds on the work of Faust (1998).

\subsection{Structural VAR Model}

Letting $y_{t}$ denote a $K \times 1$ vector of time-varying observables, this stochastic structure can be expressed in terms of the vector moving average representation:

$$
y_{t}=\Phi(L) \epsilon_{t}
$$

where $\Phi(L)=I+\Phi_{1} L+\Phi_{2} L^{2}+\cdots$ is a matrix polynomial in the lag operator, $L$, and $\epsilon_{t}$ denotes the $K \times 1$ vector of the reduced-form VAR innovations. The MB, COMP, and OCR are given by the first, second, and third elements of $y_{t}$, respectively. The structural vector moving average representation can thus be written as follows:

$$
y_{t}=\Psi(L) \xi_{t},
$$

where $\Psi(L)=I+\Psi_{1} L+\Psi_{2} L^{2}+\cdots$, and $\xi_{t}$ denotes the $K \times 1$ vector of the structural shocks.

Let $\xi_{t}^{M P}$ be the $3 \times 1$ policy shock vector $\xi_{t}^{M P}=\left[\xi_{t}^{U Q N}, \xi_{t}^{U Q L}, \xi_{t}^{C S R}\right]^{\prime}$, where $\xi_{t}^{U Q N}, \xi_{t}^{U Q L}$, and $\xi_{t}^{C S R}$ denote unconventional quantitative, qualitative, and conventional short-term monetary policy shocks, respectively. The space spanned by the policy shock vector $\xi_{t}^{M P}$ is disentangled from the space spanned by other possible shocks of the $(K-3) \times 1$ vector $\xi_{t}^{X}$ in the following linear relation between the reduced-form VAR innovations $\epsilon_{t}$ and structural shocks $\xi_{t}$ :

$$
\epsilon_{t}=R \xi_{t}=R^{M P} \xi_{t}^{M P}+R^{X} \xi_{t}^{X}, \underset{(K \times K)}{R}=\left[R_{(K \times 3)}^{R^{M P}}, \underset{(K \times(K-3))}{R^{X}}\right], \underset{(K \times 1)}{\xi_{t}}=\left[\underset{(3 \times 1)^{\prime}((K-3) \times 1)}{\xi_{(K P}^{M P}}\right]^{\prime},
$$

where $R^{M P}$ represents the impact matrix for the responses of the VAR variables $y_{t}$ to the monetary policy shocks. 
The variance-covariance matrix of the space spanned by the monetary policy shocks can be expressed as,

$$
\Sigma^{M P}=R^{M P} E\left(\xi_{t}^{M P} \xi_{t}^{M P^{\prime}}\right) R^{M P^{\prime}}=R^{M P} R^{M P^{\prime}}
$$

where the variance of monetary policy shocks is normalized to one. To distinguish a conventional policy shock from an unconventional one, we impose a restriction in which unconventional policy shocks have no contemporaneous effects on the level of the policy rate. More specifically, we can express this restriction as follows:

$$
R^{M P}=\left(\begin{array}{c}
R_{1: 3,1: 3}^{M P} \\
R_{4: K, 1: 3}^{M P}
\end{array}\right)=\left(\begin{array}{ccc}
r_{M B}^{U Q N} & r_{M B}^{U Q L} & r_{M B}^{C S R} \\
r_{C O M P}^{U Q N} & r_{C O M P}^{U Q L} & r_{C O M P}^{C S R} \\
0 & 0 & r_{C R}^{C S R} \\
r_{X K-4}^{U Q N} & r_{X K-4}^{U Q L} & r_{X K-4}^{C S R} \\
\vdots & \vdots & \vdots \\
r_{X K}^{U Q N} & r_{X K}^{U Q L} & r_{X K}^{C S R}
\end{array}\right)
$$

\subsection{Controlling the Endogeneity of the Monetary Policy Indicators}

We use the monetary policy surprises extracted from the changes in the twelve major financial markets on MPM days as the instrumental variables of the reduced-form VAR innovations, $\epsilon_{t}$. Thus, we aim to control for the endogeneity of the monetary policy indicators and disentangle the causal effects of the policy shocks on the VAR variables at the shock arrival time. More concretely, we conduct the following system regression:

$$
\epsilon_{t}=\underset{(K \times 3)}{R^{M P S}} \underset{(3 \times 1)}{\operatorname{P}} \underset{S_{t}}{ }+e_{t}
$$

where $M P S_{t}$ denotes the $3 \times 1$ vector of the three monetary policy surprises at a monthly frequency. The system regression yields the instantaneous responses of the VAR variables to the monetary policy shocks in the form of fitted values $\hat{R}^{M P S} M P S_{t}$. We then obtain the following variance-covariance matrix involving the contemporaneous impacts of the monetary 
policy shocks to the VAR variables:

$$
\hat{\Sigma}^{M P}=\hat{R}^{M P S} M P S_{t} M P S_{t}^{\prime} \hat{R}^{M P S^{\prime}} .
$$

\subsection{Identifying Unconventional Policy Shocks}

Here, we describe the second-step procedure to identify the conventional and unconventional monetary policy shocks. Specifically, we consider restrictions to extract the three types of structural shocks associated with the conventional and unconventional policy indicators from variance-covariance matrix (8), in which the endogeneity of the policy indicators is controlled for by the monetary policy surprises.

We identify the unconventional monetary policy shocks with help from MB and COMP, policy indicators that move gradually and meet their target levels soon after the BOJ's public statements on MPM days. To incorporate this feature into our identification of the unconventional monetary policy shocks, we define them as the surprise components of monetary policy that best explain the current and future paths of the MB and COMP.

This identification strategy requires that we model the revisions in the expectations of agents regarding the current and future paths of the unconventional policy indicators. We do so by employing the MFEV approach proposed by Faust (1998) and Francis et al. (2014). ${ }^{11}$ This approach allows us to specify the revisions in the agents' expectations as maximization problems for the contributions of the unconventional policy shocks to the forecast error variances of the unconventional policy indicators.

To explain the MFEV approach, we begin by expressing the $h$-step-ahead forecast error conditioning on the structural shocks $\xi_{t}$ :

$$
y_{t+h}-E_{t-1} y_{t+h}=\sum_{\tau=0}^{h} \Phi_{\tau} R \xi_{t+h-\tau}=\sum_{\tau=0}^{h} \Phi_{\tau} R^{M P} \xi_{t+h-\tau}^{M P}+\sum_{\tau=0}^{h} \Phi_{\tau} R^{X} \xi_{t+h-\tau}^{X}
$$

\footnotetext{
${ }^{11}$ Uhlig (2004), Barsky and Sims (2011), and Kurmann and Otrok (2013) employed the MFEV approach to identify news shocks, or anticipated shocks, about future technology. Zeev et al. (2015) used this approach to identify anticipated monetary policy shocks in the United States.
} 
where the first and second equalities use equations (2) and (4). Therefore, the $h$-step-ahead forecast error due to monetary policy shocks $\xi_{t+\tau}^{M P}$ can be expressed as:

$$
\sum_{\tau=0}^{h} \Phi_{\tau} R^{M P} \xi_{t+h-\tau}^{M P}=\sum_{\tau=0}^{h} \Phi_{\tau} \tilde{R}^{M P} D^{M P} \xi_{t+h-\tau}^{M P}
$$

where $\tilde{R}^{M P}$ represents the following $K \times 3$ orthogonalization matrix:

$$
\tilde{R}^{M P}=\left(\begin{array}{ccc}
\tilde{r}_{11} & 0 & 0 \\
\tilde{r}_{21} & \tilde{r}_{22} & 0 \\
\tilde{r}_{31} & \tilde{r}_{32} & \tilde{r}_{33} \\
\vdots & \vdots & \vdots \\
\tilde{r}_{K 1} & \tilde{r}_{K 2} & \tilde{r}_{K 3}
\end{array}\right),
$$

and $D^{M P}$ denotes the $3 \times 3$ orthonormal matrix $\left(D^{M P} D^{M P^{\prime}}=I\right) \cdot{ }^{12}$ Thus, the share of the $h$-step-ahead forecast error variance of monetary policy indicator $i$ attributable to monetary policy shock $\xi_{t}^{M P, j}$ is expressed as a variance decomposition of the following form:

$$
\Omega_{i, j}^{M P}(h)=\frac{e_{1 i}^{\prime}\left(\sum_{\tau=0}^{h} \Phi_{\tau} \tilde{R}^{M P} D^{M P} e_{2 j} e_{2 j}^{\prime} D^{M P^{\prime}} \tilde{R}^{M P^{\prime}} \Phi_{\tau}^{\prime}\right) e_{1 i}}{e_{1 i}^{\prime}\left(\sum_{\tau=0}^{h} \Phi_{\tau} \Sigma^{M P} \Phi_{\tau}^{\prime}\right) e_{1 i}}=\frac{\sum_{\tau=0}^{h} \Phi_{i, \tau} \tilde{R}^{M P} d_{j} d_{j}^{\prime} \tilde{R}^{M P^{\prime}} \Phi_{i, \tau}^{\prime}}{\sum_{\tau=0}^{h} \Phi_{i, \tau} \Sigma^{M P} \Phi_{i, \tau}^{\prime}}
$$

where $e_{1 i}$ and $e_{2 j}$ are the $K \times 1$ and $3 \times 1$ selection vectors, with one in the $i$ th place and $j$ th place and zeros elsewhere, and $d_{j}$ is the $3 \times 1$ vector indicating the $j$ th column of the orthonormal matrix $D^{M P}$. This variance decomposition models the revisions in an agent's expectations about the current and future path of policy indicator $i$ at the time policy shock $j$ emerges, where $i(i=1,2,3)$ indicates the place of the monetary policy indicators (MB, COMP, OCR $)$ in vector variable $y_{t}$, and $j(j=1,2,3)$ indicates the place of monetary policy

\footnotetext{
${ }^{12}$ In practice, we obtain an orthogonalization matrix $\tilde{R}^{M P}$ as follows. First, we perform a Cholesky decomposition of the $3 \times 3$ upper left submatrix $\hat{\Sigma}_{1: 3,1: 3}^{M P}$ of variance-covariance matrix (8), such that $\hat{\Sigma}_{1: 3,1: 3}^{M P}=$ $\tilde{R}_{1: 3,1: 3}^{M P} \tilde{R}_{1: 3,1: 3}^{M P^{\prime}}$. Then we calculate an orthogonalization matrix $\tilde{R}^{M P}=\hat{R}^{M P S}\left(\hat{R}_{1: 3,1: 3}^{M P S}\right)^{-1} \tilde{R}_{1: 3,1: 3}^{M P}$ using the $3 \times 3$ upper left submatrix $\hat{R}_{1: 3,1: 3}^{M P S}$ of the impact matrix $\hat{R}^{M P S}$ for the responses of the VAR variables $y_{t}$ to the monetary policy surprises.
} 
shocks $\xi_{t}^{U Q N}, \xi_{t}^{U Q L}$, and $\xi_{t}^{C S R}$ in policy shock vector $\xi_{t}^{M P}$.

Note that $\tilde{R}^{M P} d_{j}$ is the $K \times 1$ vector corresponding to the $j$ th column of a possible orthogonalization in equation (11), and thus interprets the contemporaneous impact of the $j$ th monetary policy shock on the VAR variables. If we have estimate $\hat{d}_{j}$, we can therefore generate the impulse responses of the VAR variables to the $j$ th monetary policy shock by using the estimated impact vector $\tilde{R}^{M P} \hat{d}_{j}$.

We employ the MFEV approach to identify the quantitative, qualitative, and conventional monetary policy shocks. More concretely, we begin by identifying the quantitative monetary policy shock, $\xi_{t}^{U Q N}$, satisfying the following conditions:

$$
\hat{d}_{U Q N}=\arg \max \Omega_{M B, U Q N}(h)=\frac{\sum_{\tau=0}^{h} \Phi_{M B, \tau} \tilde{R}^{M P} d_{U Q N} d_{U Q N}^{\prime} \tilde{R}^{M P^{\prime}} \Phi_{M B, \tau}^{\prime}}{\sum_{\tau=0}^{h} \Phi_{M B, \tau} \Sigma^{M P} \Phi_{M B, \tau}^{\prime}},
$$

s.t.

$$
\begin{gathered}
\tilde{r}_{31} d_{1, U Q N}+\tilde{r}_{32} d_{2, U Q N}+\tilde{r}_{33} d_{3, U Q N}=0 \\
d_{U Q N}^{\prime} d_{U Q N}=1,
\end{gathered}
$$

Under constraint (13), the quantitative shock, $\xi_{t}^{U Q N}$, has no contemporaneous effect on the OCR. This constraint reflects the central bank's practice of implementing the unconventional monetary policy when the conventional policy option of controlling the short-term interest rate is unavailable. Constraint (14) ( $d_{U Q N}$ have unit length) ensures that $d_{U Q N}$ is the first column vector belonging to orthonormal matrix $D^{M P}$. After obtaining $\hat{d}_{U Q N}$ by solving the above maximization problem, we calculate the impulse responses of the VAR variables to the quantitative monetary policy shocks using estimated impact vector $\tilde{R}^{M P} \hat{d}_{U Q N}$.

Next, we identify the qualitative and conventional monetary policy shocks. Specifically, we identify the qualitative monetary shocks $\xi_{t}^{U Q L}$ by solving the following maximization 
problem:

$$
\hat{d}_{U Q L}=\arg \max \Omega_{C O M P, U Q L}(h)=\frac{\sum_{\tau=0}^{h} \Phi_{C O M P, \tau} \tilde{R}^{M P} d_{U Q L} d_{U Q L}^{\prime} \tilde{R}^{M P^{\prime}} \Phi_{C O M P, \tau}^{\prime}}{\sum_{\tau=0}^{h} \Phi_{C O M P, \tau} \Sigma^{M P} \Phi_{C O M P, \tau}^{\prime}},
$$

s.t.

$$
\begin{gathered}
\tilde{r}_{31} d_{1, U Q L}+\tilde{r}_{32} d_{2, U Q L}+\tilde{r}_{33} d_{3, U Q L}=0, \\
d_{U Q N}=\hat{d}_{U Q N}, \\
d_{U Q L}^{\prime} d_{U Q L}=1,
\end{gathered}
$$

Under constraint (16), as under constraint (13) before, the qualitative policy shock has no contemporaneous impact on the OCR. Constraints (17) and (18) ensure that the qualitative shock is orthogonal to the quantitative shock identified in advance. In the identification of the qualitative shock, the second column in $R^{M P} \xi_{t}^{M P}$ is orthogonal to the first column obtained in maximization problems (12) through (14). This implies that, in the qualitative shock with a predetermined target level for the MB given, the central bank aims to change the composition of its assets through, for example, an operation twist. ${ }^{13}$ We can compute the impulse responses to the qualitative monetary policy shocks using estimated impact vector $\tilde{R}^{M P} \hat{d}_{U Q L}$. In the identification of the conventional monetary policy shock $\xi_{t}^{C S R}$, the third column in $R^{M P} \xi_{t}^{M P}$ is orthogonal to the first and second columns obtained through the above maximization problems and the surprise component of monetary policy has a contemporaneous impact on the OCR.

\footnotetext{
${ }^{13}$ In the quantitative and qualitative monetary easing from March 2013, the BOJ targets an annual increase of 60 to 70 trillion yen ( 80 trillion yen from October 2014) for a yearly expansion of the monetary base. To meet this target level for the monetary base, the BOJ purchases exchange trade funds, commercial papers, and long-term government bonds. Given the predetermination of the target level for the monetary base, the recursive restriction for the quantitative and qualitative shocks is plausible.
} 


\section{Estimation Results for Unconventional Monetary Pol- icy Shocks}

In this section we discuss the empirical results obtained using the monetary policy shocks identified by the method presented in the previous section. We focus on unconventional monetary policy shocks in particular. In addition to the three monetary policy indicators (MB, COMP, OCR), we include six macroeconomic variables in constructing the VAR: two asset market prices, three real economic variables, and one price indicator. The two asset market prices are the stock price index, SP, and the 10-year government bond yield, 10YJGB. The three real economic variables are the one-year real interest rate, 1YREAL; the ratio of the commercial bank's safe assets (JGB holdings) versus risky assets (equity holdings and bank lending), SAFE/RISK; and the index of industrial production, IIP. The consumer price index, CPI, is included as the price indicator. As discussed below, we also include other candidates for the VAR variables to conduct robustness checks. We set the lag length to one in the reduced-form VAR estimation based on the Bayesian information criteria.

\subsection{Conventional and Unconventional Monetary Policy Shocks}

Here we report the statistical relevance between the reduced-form VAR innovations and monetary policy surprises. Table 2 shows the estimation results for the system regression of the reduced-form VAR innovations on the three monetary policy surprises:

$$
\hat{\epsilon}_{t}^{k}=\sum_{p c=1}^{3} r_{k, p c}^{M P} M P S_{t}^{p c}+\tilde{\epsilon}_{t}^{M P, k}
$$

The monetary policy surprises seem to explain substantial proportions of the reducedform VAR innovations. In particular, the asset prices (SP and 10YJGB) appear to quickly respond to the monetary policy surprises. On the contrary, the monetary policy surprises explain little of the monetary policy indicators (MB, COMP, OCR) when the shock arrives. 
The insignificance of the conventional policy indicator, or the policy rate, can be attributed to its inaction for most of our sample period from 1998 owing to the extremely low interest rate regime in Japan.

Table 3 presents the results for the variance decomposition of the three monetary policy indicators attributable to the monetary policy shocks for $h=0,12,24,36$, and 48 months ahead: $\Omega_{M B, j}^{M P}(h), \Omega_{C O M P, j}^{M P}(h)$ and $\Omega_{O C R, j}^{M P}(h)$, where $j$ is the quantitative, qualitative, and conventional policy shock.

As the table clearly shows, the quantitative shock substantially accounts for the variations in the MB controlled by our external instruments, or the monetary policy surprises, while the conventional policy shock accounts for them to some degree, as well. ${ }^{14}$ The quantitative and conventional monetary policy shocks appear to contribute greatly to the variation in the future COMP adjusted for the monetary policy shocks. The conventional policy shock explains all of the variation in the OCR for $h=0$ according to our identification of this shock. After the first impact, however, the contribution of the quantitative shock to the variation in the OCR appears to increase at only a gradual rate.

\subsection{Impulse Response Analysis}

In this subsection we describe the estimated impulse responses to the exogenous monetary policy shocks. Figures 6 to 8 outline the estimated impulse responses to the quantitative, qualitative, and conventional monetary policy shocks of one standard deviation, respectively.

As Figure 6 shows, the quantitative easing shock leads to a gradual and continuous increase in the MB without affecting it immediately. As such, the quantitative shock can be identified as a news shock linked to the expansion of the balance sheet (i.e., agents expect the $\mathrm{MB}$ to reach its target level soon after the BOJ announces its new target). The quantitative easing shock also leads to a slow increase in the COMP, clearly indicating that the BOJ tends

\footnotetext{
${ }^{14}$ Note that most of the variance in the $\mathrm{MB}$ at $h=0$ is attributable to qualitative easing shocks. However, the sum of the contribution of the three types of monetary policy shocks to the MB is economically negligible. Hence, this finding implies that the forecast variance in the MB at $h=0$ cannot be explained by monetary policy shocks.
} 
to increase unconventional assets more than conventional assets in the process of raising the size of its balance sheet. ${ }^{15}$

For the estimated responses of nominal interest rates, the long-term nominal interest rate, 10YJGB, falls immediately, while the OCR decreases gradually and reaches its bottom one year later. A quantitative easing shock thus has a policy duration effect that decreases long-term interest rates immediately by working as a signal about the future path of policy rates.

The quantitative easing shock confers no favorable effects on the SP or SAFE/RISK, causing the former to decline and the latter to rise. We can infer, from the estimation results, that the quantitative easing shock was in no way instrumental in bringing about a portfolio rebalance where financial institutions with safer assets could be expected to lend more and increase the purchase of relatively risky assets, including stocks. Rather, the quantitative easing shock appeared to merely alter supply/demand relationships in the Japanese government bond market or change the market's expectations on the duration of the zero interest rate policy.

Consistent with this inference, the quantitative easing shock brought about a less than favorable effect on the IIP and CPI, as well. ${ }^{16}$ Given that this shock significantly decreases the long-term nominal interest rate, we can infer that the interest rate channel through the decrease in the long-term nominal interest rate due to quantitative easing fails to bring about the intended effects under Japan's unconventional monetary policy regime.

As we see in Figure 7, the qualitative easing shock has a significant effect on the COMP without imparting a contemporaneous impact. More concretely, the COMP peaks almost six months later. On the contrary, the MB shows no significance response to the qualitative easing shock. In contrast to the quantitative easing shock, the qualitative easing shock leads

\footnotetext{
${ }^{15}$ In fact, the BOJ often faced an underbidding of securities purchases, where bids fell short of offers, in its open market operations to inject liquidity. This may have been a consequence of the lack of market demand for liquidity.

${ }^{16}$ Hayashi and Koeda (2014) found that exiting from the quantitative easing policy is expansionary if the actual-to-required reserve ratio is not unduly large.
} 
to a substantive increase in SP, a decrease in the 10YJGB, and a decrease in SAFE/RISK. These findings imply that qualitative easing induces financial institutions to increase the purchase of risky assets and lend more. The BOJ's larger purchases of unconventional assets under qualitative easing resulted in a tight supply/demand balance in the long-term Japanese government bond market and a rise in the prices of long-term Japanese government bonds. We also observe a portfolio rebalance in response to the qualitative easing shocks.

For the estimated responses of the other real economic variables, 1YREAL decreases continuously in response to the qualitative easing shock, implying that qualitative easing raises inflation expectations while bringing about little change in the short-term nominal interest rate. The IIP and CPI both increase significantly.

Figure 8 shows that the conventional policy shock basically produces similar impulse responses to those demonstrated in the VAR literature (Bernanke and Blinder (1992), Christiano et al. (1996), and Bernanke and Mihov (1998) for U.S. monetary policy, and Miyao (2000, 2002), Fujiwara (2006), Nakashima (2006), and Shibamoto (2016) for Japanese monetary policy), although the initial responses of some the variables seem to differ. In the identification of the conventional policy shock, the OCR substantially falls after the shock arrives. This conventional policy shock leads to an increase in the MB and a decrease in the COMP.

The estimated impulse responses of the SP are not significant for about one year, but increase continuously from one year to three years following the conventional policy shock. The 10YJGB, the long-term nominal interest rate, appears not to significantly respond to the conventional policy shock.

The one-year real interest rate, 1YREAL, begins to fall after the OCR and returns to the pre-shock level about a year later, which shows that the inflation rate starts to increase from that period. From the negative responses of SAFE/RISK, we can infer that the conventional policy shock causes a portfolio rebalance even during this low interest rate period.

The conventional policy easing shock leads to increases in both the IIP and CPI, although 
the former shows a decrease in the first few periods. ${ }^{17}$ The IIP peaks after the CPI begins to increase about two years following the conventional policy shock.

\subsection{Exogeneity of Monetary Policy Shocks}

In the previous sections we showed that qualitative easing shocks have favorable effects on the real economy while quantitative shocks do not. Our results, however, may arise from correlations between our monetary policy shocks and other determinants of the real economy.

To demonstrate the plausibility of our monetary policy shocks, we examine the associations among the nine variables in the VAR and the global economic variables out of the VAR. Although our identified policy shocks can be independently determined from global economic factors, the linkages between the Japanese economy and global economy allow us to determine the reduced-form VAR innovations of the policy indicators endogenously. From this analytical viewpoint, we conduct the following regression of the VAR forecast errors on the global economic factors:

$$
\hat{\epsilon}_{t}^{k}=\sum_{l} r_{k, l}^{x} x_{t}^{l}+\tilde{\epsilon}_{t}^{x, k}
$$

where $\hat{\epsilon}_{t}^{k}$ denotes the VAR innovations estimated from the nine-variable VAR and $x_{t}^{l}$ denotes the global economic variables expected to have substantive effects on the Japanese economy.

Table 4 shows that the oil price, OIL, is positively associated with the forecast errors of the short-term nominal interest rate (OCR), 1YREAL, and CPI. This finding tells us that the OCR rises as an endogenous response to increases in inflation rates and inflation expectations. The U.S. index of industrial production, USIP, is negatively associated with the VAR innovations of the long-term nominal interest rate (10YJGB). We can infer, from these estimates, that the decline in the U.S. economy is significantly associated with the increase in the demand for Japanese government bonds. Turning to the interrelation among stock market prices, the U.S. stock price index (USSP) is positively and substantively associated

\footnotetext{
${ }^{17}$ The first decline in the IIP can be explained by the revisions of the expectations of market participants and firms regarding future economic conditions, revisions caused by conventional monetary policy shocks, as Romer and Romer (2000) pointed out.
} 
with the VAR innovations of the Japanese stock price index (SP).

When we look at the endogenous response of monetary policy to global financial fragility, the TED spread is positively associated with the forecast errors of the BOJ's COMP. Further, the federal funds rate is positively associated with the OCR. These findings imply that the financial fragility in the U.S. is associated with the BOJ's qualitative easing and a decrease in the policy rate.

In the next exercise we examine whether our identified monetary policy shocks can be determined from the above global economic variables using the following auxiliary regression:

$$
\hat{\xi}_{t}^{M P, j}=\sum_{l} r_{j, l}^{x} x_{t}^{l}+\epsilon_{\xi, t}^{M P, j}
$$

where $\hat{\xi}_{t}^{M P, j}$ represents each of the qualitative, quantitative, and conventional monetary policy shocks. As Table 5 shows, none of the monetary policy shocks is significantly associated with the global economic variables at the $5 \%$ significance level. This estimation result ensures that our monetary policy shocks are exogenous to global economic shocks. ${ }^{18}$

The above analysis suggests that Japanese monetary policy endogenously responds to the global economic conditions. Hence, the simple use of the reduced-form VAR innovations of the monetary policy indicators can cause us to erroneously estimate the policy effects. Hence, we use our monetary policy shocks to disentangle the exogenous responses of the economy to monetary policy shocks from the endogenous responses.

\subsection{Robustness Check}

Here we discuss the robustness of the impulse response analysis. In the previous subsection we demonstrated that our monetary policy surprises are useful as exogenous instruments to estimate monetary policy effects in terms of whether our monetary policy shocks are exoge-

\footnotetext{
${ }^{18}$ As an exception, the U.S. stock price index, USSP, is positively associated with the quantitative policy easing and the conventional policy easing at the $10 \%$ significance level. This finding implies that Japanese monetary policy shocks have an effect on U.S. stock prices under the unconventional monetary policy regime.
} 
nous to global economic conditions. Yet as we discuss in the Appendix, we take no explicit steps, in constructing the monetary policy surprises, to control for macroeconomic news about Japan's real economic activity or inflation in the dynamic factor model (see equation (22) in the Appendix). Hence, our monetary policy surprises could include information on the macroeconomic news other than the monetary policy itself. We found, however, that even if we explicitly controlled for the macroeconomic news in the construction of the monetary policy surprises, the estimated impulse responses were no different from those reported in Subsection $4.2 .^{19}$

We also conducted a robustness check on the impulse responses by including in the VAR model the all-industry activity index, unemployment rate, and index for the shipment of investment goods, instead of the IIP. While these alternative variables provided no favorable real effects for the quantitative easing shocks, they did provide favorable real effects for the qualitative easing shocks.

The above robustness checks for the impulse responses to our monetary policy shocks support the empirical results reported in Subsection 4.2.

\subsection{Unconventional Monetary Policy Effects}

We have thus far found that quantitative easing shocks have no favorable effects on the real economy, although they do precipitate decreases in the long-term nominal interest rate, as expected by the BOJ. On the contrary, qualitative easing shocks cause favorable effects not only on the long-term interest rate, but also on real economic activity. In this subsection we draw from these findings to propose two hypotheses about the unconventional policy effects for future research.

One hypothesis holds that the ineffectiveness of quantitative easing shocks can be ex-

\footnotetext{
${ }^{19}$ More precisely, we controlled for the macroeconomic news on MPM days in the factor model, $X_{t}=$ $\Lambda F_{t}+\Gamma \cdot N E W S_{t}+e_{t}$, where $X_{t}$ represents the twelve financial market variables, $F_{t}$ represents common factors as monetary policy surprises, and $N E W S_{t}$ represents macroeconomic news dummies. We included five news dummies that take a value of one if news about the GDP, unemployment rate, IIP, CPI and Producer Price Index is published on the MPM days.
} 
plained by their effect in raising concern about the future fragility of the real economy. According to Romer and Romer (2000), Ellingsen and Söderstrom (2001), Claus and Dungey (2012), Campbell et al. (2012), and Nakamura and Steinsson (2017), monetary policy actions provide the public with signals of the central bank's information. If the quantitative easing by the BOJ worked as a signal presaging future decreases in output and inflation, this signal would suppress firm investment and wage growth.

Another hypothesis involves economic uncertainty and its effect in instilling a caution in real economic activity. Bekaert et al. (2013) used stock market option-based implied volatility data, or VIX data, to demonstrate that conventional policy easing by lowering the short-term interest rate decreases economic uncertainty, which in turn leads to favorable effects on the real economy (see also Aastveit et al. (2013) and Creal and $\mathrm{Wu}(2016)) .{ }^{20}$ If the quantitative easing shock elevates economic uncertainty while the qualitative easing shock contributes to its reduction, the difference in the estimated responses of the real economic variables to the two unconventional policy shocks could be explained along this line (Nakashima et al. $(2017)) \cdot{ }^{21}$

\section{Conclusion}

Previous research has found favorable effects of the unconventional monetary policy. Previous studies may take a flawed approach in the policy evaluation by assuming either that the MB is the central bank's only unconventional monetary policy measure or that the underlying unconventional monetary policy shocks can be captured by one variable alone. They neglect

\footnotetext{
${ }^{20}$ In terms of the instability in investors' inflation expectations, Gürkaynak and Wright (2012) pointed out that the instability could come from a lack of central bank credibility, a problem that might drive a wedge between actual and perceived inflation targets.

${ }^{21}$ Using the volatility index Japan (VXJ), which is in strict accordance with the Chicago Board Options Exchange approach underlying the VIX, Nakashima et al. (2017) found that the quantitative easing shock would increase the VXJ, while the qualitative easing shock would decrease it. Following Bekaert et al. (2013), Nakashima et al. (2017) decomposed the VXJ into a proxy for risk aversion and a proxy for uncertainty. Nakashima et al. (2017) concluded that an increasing effect on the VXJ implied that the quantitative easing shock reduced risk appetite and worsened uncertainty, while the decreasing effect implied that the qualitative easing shock improved them.
} 
to distinguish between quantitative and qualitative monetary policy shocks in both cases, which prevents them from correctly disentangling the policy effects. We proposed a new method to separately identify the two unconventional policy shocks and conventional policy shock, using the unconventional monetary policy in place in Japan since 1999.

Previous policy evaluations of unconventional policy effects have also been criticized for assuming that the unconventional monetary policy shock should be embodied as the reducedform VAR innovations in the MB. This type of identification is the usual method for assessing the conventional monetary policy, in which the central banks aim to control the policy rates. Quantitative and qualitative policy measures, meanwhile, differ from the policy rate in an important respect: by their very nature, both show no immediate responses to the public statements of the central banks on adjustments in their target levels. Our identification method incorporates this feature by defining the two unconventional policy shocks as news shocks that portend the current and future paths of the two policy measures.

We find that the quantitative easing shock, which involves a gradual increase in the size of the BOJ's balance sheet, has contractionary effects on the macroeconomy, while the qualitative easing shock, which involves a gradual increase in the ratio of the BOJ's unconventional asset to its total assets, yields expansionary effects. Both shocks, meanwhile, significantly decrease the long-term nominal interest rate. Our future research will aim to explore why these two unconventional policy shocks yield such different policy effects along the lines suggested in this paper.

\section{Appendix: Procedure for Constructing the Monetary Policy Surprises}

We construct the monetary policy surprises from high-frequency daily trading data on the major financial markets just before and just after the BOJ's public statements. More concretely, we employ the principal component analysis method of Bernanke et al. (2004) and 
Gürkaynak et al. (2005b) and then prepare the monetary policy surprises as common factors of unanticipated changes in the major financial market variables following the public statements.

The principal component analysis method is based on the following factor model:

$$
X_{t}=\Lambda F_{t}+e_{t}
$$

where $X_{t}$ is the vector of $n$ financial times series where all series are transformed as stationary in the rate of changes just before and just after the BOJ's public statements; $e_{t}$ is the vector of $n$ idiosyncratic disturbance terms; $F_{t}$ is the vector of $r$ unobserved common factors, and $\Lambda$ is an $n \times r$ matrix of coefficients called factor loadings. We aim to use the principal component analysis to extract common factors, $F_{t}$.

Twelve financial market variables are included in $X_{t}$ : one futures rate (the three-month euro-yen TIBOR futures rate), five yen interest swap rates (the one-year, two-year, five-year, 10-year, and 30-year yen interest swap rates), one short-term spot rate (the three-month euro-yen TIBOR rate), two spot exchange rates (the Yen-U.S. dollar spot exchange rate and Yen-AUS dollar spot exchange rate in the Tokyo market), two stock price indexes (TOPIX and Nikkei Jasdaq index), and bank reserve deposits. For the seven rate variables, we include their rates of change before and after the public statements. For the exchange rates, stock price indexes, and bank reserve deposits, we include their log-differences as percentages of their rates of change.

The twelve markets close at 3:00 p.m. The BOJ usually holds a press conference at 3:30 p.m. after the MPM, and media such as Bloomberg then convey the news about the BOJ's policy decisions. To duly consider the timing of the news release and the time required for sufficient recognition of the news, we use the closing values from the day before the public statement to the day after the statement to calculate changes over a two-day period for the twelve financial variables. ${ }^{22}$

\footnotetext{
${ }^{22}$ An event study analysis by Ueda (2012) showed that asset prices, including TOPIX and Japanese gov-
} 
We preliminarily exclude the MPM dates when the BOJ decided to coordinate policy with the Federal Reserve Bank, the European Central Bank, and the Bank of England and when the BOJ determined the policy measures to be taken after the Tohoku earthquake on March 11, 2011, on the presumption that the policy coordination and disaster event would contaminate the BOJ's policy effects. ${ }^{23}$

To select the number of common factors, we employ the information criteria proposed by Bai and Ng (2002) and Ahn and Horenstein (2013). The two information criteria suggest that we should adopt three common factors as monetary policy surprises in the twelve financial markets. When constructing monthly data on the monetary policy surprises, we aggregate two datasets of the three common factors, each of which is generated on two MPM days per month.

ernment bond yields, significantly respond to monetary policy changes from two days after the BOJ's public statements onward.

${ }^{23}$ The BOJ held MPMs on September 18, 2008, September 29, 2008, and November 30, 2011 for the policy coordination, and on March 14, 2011 for the Tohoku earthquake. We excluded these four MPM days. 


\section{References}

Aastveit, Knut, Gisle Natvik, and Sergio Sola, "Economic Uncertainty and the Effectiveness of Monetary Policy," 2013. mimeo.

Ahn, Seung C. and Alex R. Horenstein, "Eigenvalue Ratio Test for the Number of Factors," Econometrica, May 2013, 81 (3), 1203-1227.

Bai, Jushan and Serena Ng, "Determining the Number of Factors in Approximate Factor Models," Econometrica, 2002, 70 (1), 191-221.

Barsky, Robert B. and Eric R. Sims, "News shocks and business cycles," Journal of Monetary Economics, January 2011, 58 (3), 273-289.

Baumeister, Christiane and Luca Benati, "Unconventional Monetary Policy and the Great Recession: Estimating the Macroeconomic Effects of a Spread Compression at the Zero Lower Bound," International Journal of Central Banking, 2013, 9, 165-212.

Bekaert, Geert, Marie Hoerova, and Marco Lo Duca, "Risk, Uncertainty, and Monetary Policy," Journal of Monetary Economics, October 2013, 60 (7), 771-788.

Bernanke, Ben S. and Alan S. Blinder, "The Federal Funds Rate and the Channels of Monetary Transmission," American Economic Review, 1992, 82 (4), 901-921.

_ and Ilian Mihov, "Measuring Monetary Policy," Quarterly Journal of Economics, 1998, $113(3), 869-902$.

- and Vincent R. Reinhart, "Conducting Monetary Policy at Very Low Short-Term Interest Rates," American Economic Review, 2004, 94 (2), 85-90.

_ , _ , and Brian P. Sack, "Monetary Policy Alternatives at the Zero Bound: An Empirical Assessment," Brookings Papers on Economic Activity, 2004, 35 (2), 1-100. 
Campbell, Jeffrey R., Charles L. Evans, Jonas D. M. Fisher, and Alejandro Justiniano, "Macroeconomic Effects of Federal Reserve Forward Guidance," Brookings Papers on Economic Activity, March 2012, 43 (1), 1-80.

Christiano, Lawrence J., Martin Eichenbaum, and Charles L. Evans, "The Effects of Monetary Policy Shocks: Evidence from the Flow of Funds," The Review of Economics and Statistics, February 1996, 78 (1), 16-34.

Claus, Edda and Mardi Dungey, "U.S. Monetary Policy Surprises: Identification with Shifts and Rotations in the Term Structure," Journal of Money, October 2012, 44 (7), $1443-1453$.

Cochrane, John H. and Monika Piazzesi, "The Fed and Interest Rate, A High-Frequency Identification," American Economic Review, February 2002, 92 (2), 90-95.

Creal, Drew D. and Jing Cynthia Wu, "Monetary Policy Uncertainty and Economic Fluctuations," Chicago Booth, Working Paper, 2016, pp. 14-23.

Ellingsen, Tore and Ulf Söderstrom, "Monetary Policy and Market Interest Rates," American Economic Review, December 2001, 91 (5), 1594-1607.

Faust, Jon, "The Robustness of Identified VAR Conclusions about Money," CarnegieRochester Conference Series on Public Policy, December 1998, 49 (1), 207-244.

_, Eric T. Swanson, and Jonathan H. Wright, "Identifying VARs Based on High Frequency Futures Data," Journal of Monetary Economics, September 2004, 51 (6), 11071131.

Francis, Neville, Michael T. Owyang, Jennifer E. Roush, and Riccardo DiCecio, "A Flexible Finite-horizon Alternative to Long-run Restrictions with an Application to Technology Shock," Review of Economics and Statistics, October 2014, 96 (4), 638-647. 
Fujiwara, Ippei, "Evaluating Monetary Policy When Nominal Interest Rates Are Almost Zero," Journal of the Japanese and International Economies, 2006, 20 (3), 434-453.

Gagnon, Joseph, Matthew Raskin, Julie Remache, and Brian P. Sack, "The Financial Market Effects of the Federal Reserve's Large-Scale Asset Purchases," International Journal of Central Banking, 2011, 7 (1), 3-43.

Gambacorta, Leonardo, Boris Hofmann, and Gert Peersman, "The Effectiveness of Unconventional Monetary Policy at the Zero Lower Bound: A Cross-Country Analysis," Journal of Money, Credit, and Banking, June 2014, 46 (4), 615-642.

Gertler, Mark and Peter Karadi, "Monetary Policy Surprises, Credit Costs, and Economic Activity," American Economic Journal: Macroeconomics, January 2015, 7 (1), 4476.

Gürkaynak, Refet S. and Jonathan H. Wright, "Macroeconomics and the Term Structure," Journal of Economic Literature, June 2012, 50 (2), 331-367.

_, Brian P. Sack, and Eric T. Swanson, "The Sensitivity of Long-Term Interest Rates to Economic News: Evidence and Implications for Macroeconomic Models," American Economic Review, March 2005, 95 (1), 425-436.

_, , and _, "Do Actions Speak Louder Than Words? The Response of Asset Prices to Monetary Policy Actions and Statements," International Journal of Central Banking, May 2005, 1 (1), 55-93.

_, _, and _, "Market-Based Measures of Monetary Policy Expectations," Journal of Business and Economic Statistics, April 2007, 25 (2), 201-212.

Hayashi, Fumio and Junko Koeda, "Exiting from QE," NBER Working Paper, February 2014, 19938. 
Honda, Yuzo and Yoshihiro Kuroki, "Financial and Capital Markets' Response to Changes in the Central Bank's Target Interest Rate: The Case of Japan," Economic Journal, 2006, 116 (513), 812-842.

_, , , and Minoru Tachibana, "An Injection of Base Money at Zero Interest Rates: Empirical Evidence from the Japanese Experience 2001-2006," Japanese Journal of Monetary and Financial Economics, August 2013, 1 (1), 1-24.

Inoue, Tomoo and Tatsuyoshi Okimoto, "Were There Structural Breaks in the Effects of Japanese Monetary Policy? Re-Evaluating Policy Effects of the Lost Decade," Journal of the Japanese and International Economies, 2008, 22 (3), 320-342.

Iwata, Shigeru and Shu Wu, "Estimating Monetary Policy Effects When Interest Rates are Close to Zero," Journal of Monetary Economics, October 2006, 53 (7), 1395-1408.

Joyce, Michael A. S., Ana Lasaosa, Ibrahim Stevens, and Matthew Tong, "The Financial Market Impact of Quantitative Easing in the United Kingdom," International Journal of Central Banking, September 2011, 7 (3), 113-161.

_, David Miles, Andrew Scott, and Dimitri Vayano, "Quantitative Easing and Unconventional Monetary Policy: An Introduction," Economic Journal, October 2012, 122 (564), 271-288.

Kapetanios, George, Haroon Mumtaz, Ibrahim Stevens, and Konstantinos Theodoridis, "Assessing the Economy-Wide Effects of Quantitative Easing," Economic Journal, November 2012, 122 (564), F316-F347.

Kimura, Takeshi and Jouchi Nakajima, "Identifying Conventional and Unconventional Monetary Policy Shocks: A Latent Threshold Approach," The B.E. Journal of Macroeconomics, January 2016, 16 (1), 277-300. 
Kurmann, André and Christopher Otrok, "News Shocks and the Slope of the Term Structure of Interest Rates," American Economic Review, October 2013, 103 (6), 26122632.

Kuttner, Kenneth N., "Monetary Policy Surprises and Interest Rates: Evidence from the Fed Funds Futures Market," Journal of Monetary Economics, 2001, 47 (3), 523-544.

Milani, Fabio and John Treadwell, "The Effects of Monetary Policy "News" and "Surprises"," Journal of Money, Credit and Banking, November 2012, 44 (8), 1667-1692.

Miyao, Ryuzo, "The Role of Monetary Policy in Japan: A Break in the 1990s?," Journal of the Japanese and International Economies, 2000, 14 (4), 366-384.

_ , "The Effects of Monetary Policy in Japan," Journal of Money, Credit, and Banking, 2002, $34(2), 376-392$.

Nakamura, Emi and Jon Steinsson, "High Frequency Identification of Monetary NonNeutrality: The Information Effect," Quarterly Journal of Economics, 2017. forthcoming.

Nakashima, Kiyotaka, "The Bank of Japan's Operating Procedures and the Identification of Monetary Policy Shocks: A Reexamination Using the Bernanke-Mihov Approach," Journal of the Japanese and International Economies, 2006, 20 (3), 406-433.

_ , Masahiko Shibamoto, and Koji Takahashi, "Unconventional Monetary Policy and Risk Taking," 2017. mimeo.

Rogers, John H., Chiara Scotti, and Jonathan H. Wright, "Evaluating Asset-Market Effects of Unconventional Monetary Policy: A Multi-Country Review," Economic Policy, October 2014, 29 (80), 3-50.

Romer, Christina D. and David H. Romer, "Federal Reserve Information and the Behavior of Interest Rates," American Economic Review, June 2000, 90 (3), 429-457. 
_ and _, "A New Measure of Monetary Shocks: Derivation and Implications," American Economic Review, September 2004, 94 (4), 1055-1084.

Shibamoto, Masahiko, "Source of Underestimation of the Monetary Policy Effect: Reexamination of the Policy Effectiveness in Japan's 1990s," The Manchester School, December 2016, 84 (6), 795-810.

Shiratsuka, Shigenori, "Size and Composition of the Central Bank Balance Sheet: Revisiting Japan's Experience of the Quantitative Easing Policy," Monetary and Economic Studies, November 2010, 28, 79-106.

Stock, James H. and Mark W. Watson, "Disentangling the Channels of the 2007-2009 Recession," Brookings Papers on Economic Activity, Spring 2012, 44 (1), 81-135.

Swanson, Eric T., "Let's Twist Again: A High-frequency Event-study Analysis of Operation Twist and Its Implications for QE2," Brookings Papers on Economic Activity, Spring 2011, 42, 151-207.

Ueda, Kazuo, "The Effectiveness of Non-Traditional Monetary Policy Measures: The Case of the Bank of Japan," Japanese Economic Review, 2012, 63 (1), 1-22.

Uhlig, Harald, "Do Technology Shocks Lead to a Fall in Total Hours Worked?," Journal of the European Economic Association, 2004, 2 (2-3), 361-371.

Wright, Jonathan H., "What does Monetary Policy do to Long-Term Interest Rates at the Zero Lower Bound?," Economic Journal, 2012, 122 (564), F447-F466.

Zeev, Nadav Ben, Christopher M. Gunn, and Hashmat Khan, "Monetary News Shocks," Carleton Economic Papers, 2015, 15-02. 
Table 1: Results for the Distributed Lag Regression of Each Monetary Policy Indicator on Monetary Policy Surprises

\begin{tabular}{ccccccc}
\hline \hline \multirow{2}{*}{ Lags } & \multicolumn{5}{c}{ Monetary Policy Indicator: $y^{M P I}$} & \\
& MB & COMP & OCR & $\Delta$ MB & $\Delta$ COMP & $\Delta$ OCR \\
\hline$H=0$ & 1.396 & 4.292 & 9.090 & 1.873 & 5.125 & 2.904 \\
& {$[0.706]$} & {$[0.232]$} & {$[0.028]$} & {$[0.599]$} & {$[0.163]$} & {$[0.407]$} \\
$H=1$ & 2.699 & 10.095 & 25.236 & 4.767 & 6.883 & 14.080 \\
& {$[0.846]$} & {$[0.121]$} & {$[0.000]$} & {$[0.574]$} & {$[0.332]$} & {$[0.029]$} \\
$H=2$ & 5.661 & 58.326 & 34.790 & 12.970 & 29.063 & 23.700 \\
& {$[0.773]$} & {$[0.000]$} & {$[0.000]$} & {$[0.164]$} & {$[0.001]$} & {$[0.005]$} \\
$H=6$ & 8.919 & 95.340 & 62.230 & 20.631 & 48.051 & 47.333 \\
& {$[0.990]$} & {$[0.000]$} & {$[0.000]$} & {$[0.482]$} & {$[0.001]$} & {$[0.001]$} \\
$H=12$ & 19.605 & 185.518 & 214.987 & 54.311 & 95.749 & 62.147 \\
& {$[0.996]$} & {$[0.000]$} & {$[0.000]$} & {$[0.052]$} & {$[0.000]$} & {$[0.011]$} \\
$H=18$ & 75.483 & 777.437 & 248.421 & 122.122 & 232.586 & 141.381 \\
& {$[0.051]$} & {$[0.000]$} & {$[0.000]$} & {$[0.000]$} & {$[0.000]$} & {$[0.000]$} \\
\hline \hline & 315.375 & 1852.061 & 682.937 & 268.248 & 567.294 & 271.981 \\
& {$[0.000]$} & {$[0.000]$} & {$[0.000]$} & {$[0.000]$} & {$[0.000]$} & {$[0.000]$} \\
\hline \multirow{2}{*}{$H=24$}
\end{tabular}

Notes: The distributed lag regression model is specified as equation (1). This table shows Chi-square statistics (their p-values in brackets) resulting from tests of the null hypothesis: $r_{M P I, p c}^{M P, h}=0$ for all $p c=1,2,3$ and $h=0, \cdots, H$.

Table 2: Results for the Regression of Each VAR Innovation on Monetary Policy Surprises

\begin{tabular}{cccccccccc}
\hline \hline & & & \multicolumn{7}{c}{ VAR Innovation: $\hat{\epsilon}^{k}$} \\
& MB & COMP & OCR & SP & 10YJGB & 1YREAL & SAFE/RISK & IIP & CPI \\
\hline$\chi^{2}$ & 4.170 & 2.301 & 2.998 & 32.436 & 15.132 & 5.429 & 6.799 & 2.719 & 1.064 \\
& {$[0.244]$} & {$[0.512]$} & {$[0.392]$} & {$[0.000]$} & {$[0.002]$} & {$[0.143]$} & {$[0.079]$} & {$[0.437]$} & {$[0.786]$} \\
\hline \hline
\end{tabular}

Notes: The regression model is specified as equation (19). This table shows Chi-square statistics (their p-values in brackets) resulting from tests of the null hypothesis: $r_{k, p c}^{M P}=0$ for all $p c=1,2,3$. 


\section{Table 3: Forecast Error Variance Decomposition of Monetary Policy Indicators}

\begin{tabular}{|c|c|c|c|c|c|c|c|c|c|}
\hline & \multicolumn{3}{|c|}{ Variance Decomposition of MB } & \multicolumn{3}{|c|}{ Variance Decomposition of COMP } & \multicolumn{3}{|c|}{ Variance Decomposition of OCR } \\
\hline & Quantitative & Qualitative & Conventional & Quantitative & Qualitative & Conventional & Quantitative & Qualitative & Conventional \\
\hline$h=0$ & 0.254 & 98.633 & 1.113 & 47.541 & 21.784 & 30.676 & 0 & 0 & 100 \\
\hline$h=24$ & 66.763 & 1.657 & 31.580 & 39.334 & 14.725 & 45.941 & 56.867 & 3.795 & 39.338 \\
\hline$h=36$ & 71.356 & 1.180 & 27.463 & 50.637 & 11.523 & 37.841 & 53.812 & 9.509 & 36.679 \\
\hline$h=48$ & 74.145 & 1.224 & 24.631 & 56.189 & 10.165 & 33.647 & 46.116 & 18.849 & 35.035 \\
\hline
\end{tabular}

Notes: This table shows the estimated percentage share of the forecast error variance $\Omega_{i . j}^{M P}(h)$ of each monetary policy indicator $i$ attributable to each monetary policy shock $j$ for $h$ months ahead.

Table 4: Results for the Regression of Each VAR innovation on Global Economic Factors

\begin{tabular}{lccccccccc}
\hline \hline \multirow{2}{*}{ Regressors } & & & \multicolumn{7}{c}{ VAR Innovation: $\hat{\epsilon}^{k}$} \\
& MB & COMP & OCR & SP & 10YJGB & 1YREAL & SAFE/RISK & IIP & CPI \\
\hline Oil & -3.554 & -3.264 & 0.121 & 2.121 & -0.209 & -0.226 & 0.002 & -1.817 & 0.229 \\
& $(2.606)$ & $(6.011)$ & $(0.045)$ & $(5.322)$ & $(0.152)$ & $(0.119)$ & $(0.012)$ & $(2.238)$ & $(0.132)$ \\
\multirow{2}{*}{ USIP } & 8.637 & 58.560 & -0.807 & -93.932 & -2.913 & -2.719 & 0.311 & 14.906 & 0.359 \\
& $(26.118)$ & $(50.972)$ & $(0.610)$ & $(63.223)$ & $(1.122)$ & $(1.875)$ & $(0.130)$ & $(34.884)$ & $(1.272)$ \\
\multirow{2}{*}{ USSP } & 9.190 & 13.783 & -0.017 & 72.483 & 0.521 & 0.225 & 0.036 & 7.311 & 0.014 \\
& $(4.918)$ & $(9.193)$ & $(0.085)$ & $(8.787)$ & $(0.256)$ & $(0.207)$ & $(0.023)$ & $(4.239)$ & $(0.235)$ \\
\multirow{2}{*}{ USTED } & -0.366 & 6.880 & 0.064 & 12.375 & 0.300 & 0.127 & 0.015 & 1.853 & -0.156 \\
& $(2.355)$ & $(3.794)$ & $(0.066)$ & $(7.317)$ & $(0.129)$ & $(0.218)$ & $(0.012)$ & $(3.795)$ & $(0.221)$ \\
\multirow{2}{*}{ FFR } & -1.345 & 0.251 & 0.000 & 1.071 & 0.075 & 0.069 & 0.001 & 0.066 & -0.007 \\
& $(1.279)$ & $(2.234)$ & $(0.022)$ & $(2.204)$ & $(0.045)$ & $(0.042)$ & $(0.006)$ & $(0.765)$ & $(0.054)$ \\
\hline$\chi^{2}$ & 4.231 & 6.828 & 10.399 & 85.956 & 17.170 & 10.095 & 12.334 & 3.256 & 4.675 \\
& {$[0.517]$} & {$[0.234]$} & {$[0.065]$} & {$[0.000]$} & {$[0.004]$} & {$[0.073]$} & {$[0.030]$} & {$[0.661]$} & {$[0.457]$} \\
\hline \hline
\end{tabular}

Notes: This table shows estimated coefficients in equation (20). Values in parentheses are standard errors. This table shows Chi-square statistics (their p-values in brackets) resulting from tests of the null hypothesis: $r_{k, l}^{x}=0$ for all $l=$ Oil,USIP,USSP,USTED,FFR. 
Table 5: Results for the Regression of Each Monetary Policy Shock on Global Economic Factors

\begin{tabular}{lccc}
\hline \hline \multirow{2}{*}{ Regressors } & \multicolumn{3}{c}{ Monetary Policy Shock: $\hat{\xi}^{M P *, j}$} \\
& Quantitative & Qualitative & Conventional \\
\hline Oil & 0.707 & 1.031 & -0.408 \\
\multirow{2}{*}{ USIP } & $(1.153)$ & $(1.216)$ & $(1.067)$ \\
& 4.614 & -5.285 & -12.472 \\
USSP & $(12.569)$ & $(12.779)$ & $(10.711)$ \\
& -5.190 & 2.022 & -2.677 \\
USTED & $(2.853)$ & $(2.999)$ & $(1.533)$ \\
& -0.371 & -1.590 & -1.383 \\
FFR & $(2.137)$ & $(1.606)$ & $(1.420)$ \\
& -0.459 & -0.025 & -0.388 \\
& $(0.483)$ & $(0.411)$ & $(0.378)$ \\
\hline$\chi^{2}$ & 3.852 & 2.512 & 6.507 \\
& {$[0.571]$} & {$[0.775]$} & {$[0.260]$} \\
\hline \hline
\end{tabular}

Notes: This table shows estimated coefficients in equation (21). Values in parentheses are standard errors. This table shows Chi-square statistics (their p-values in brackets) resulting from tests of the null hypothesis: $r_{j, l}^{x}=0$ for all $l=$ Oil,USIP,USSP,USTED,FFR. 


\section{Figure 1: Size, Unconventional Assets and Call Rate}

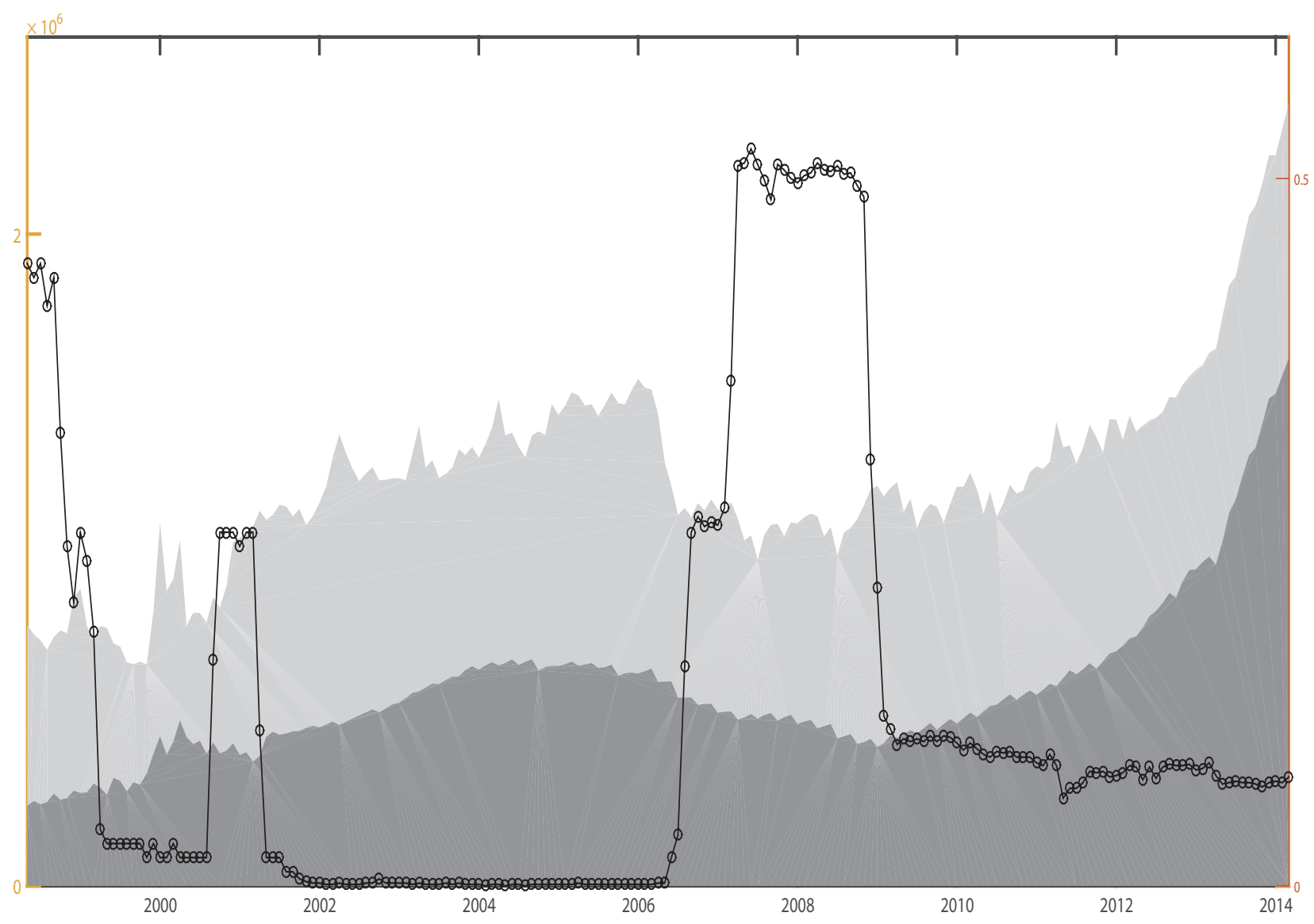

Notes: The dark gray shadow and light gray shadow indicate the amounts of unconventional assets and conventional assets held by the Bank of Japan, respectively. The amounts are shown in units of 100 trillion Yen on the left-hand scale. The plotted line indicates the call rate in $\%$ on the right hand scale. Unconventional Assets include Exchange-Traded Funds (ETF), Real Estate Investment Trusts (RIET), corporate bonds, commercial paper, longterm government bonds, asset backed securities. Conventional assets include other assets such as short-term government bonds. 
Figure 2: Monetary Policy Variables around the Introduction of ZIRP
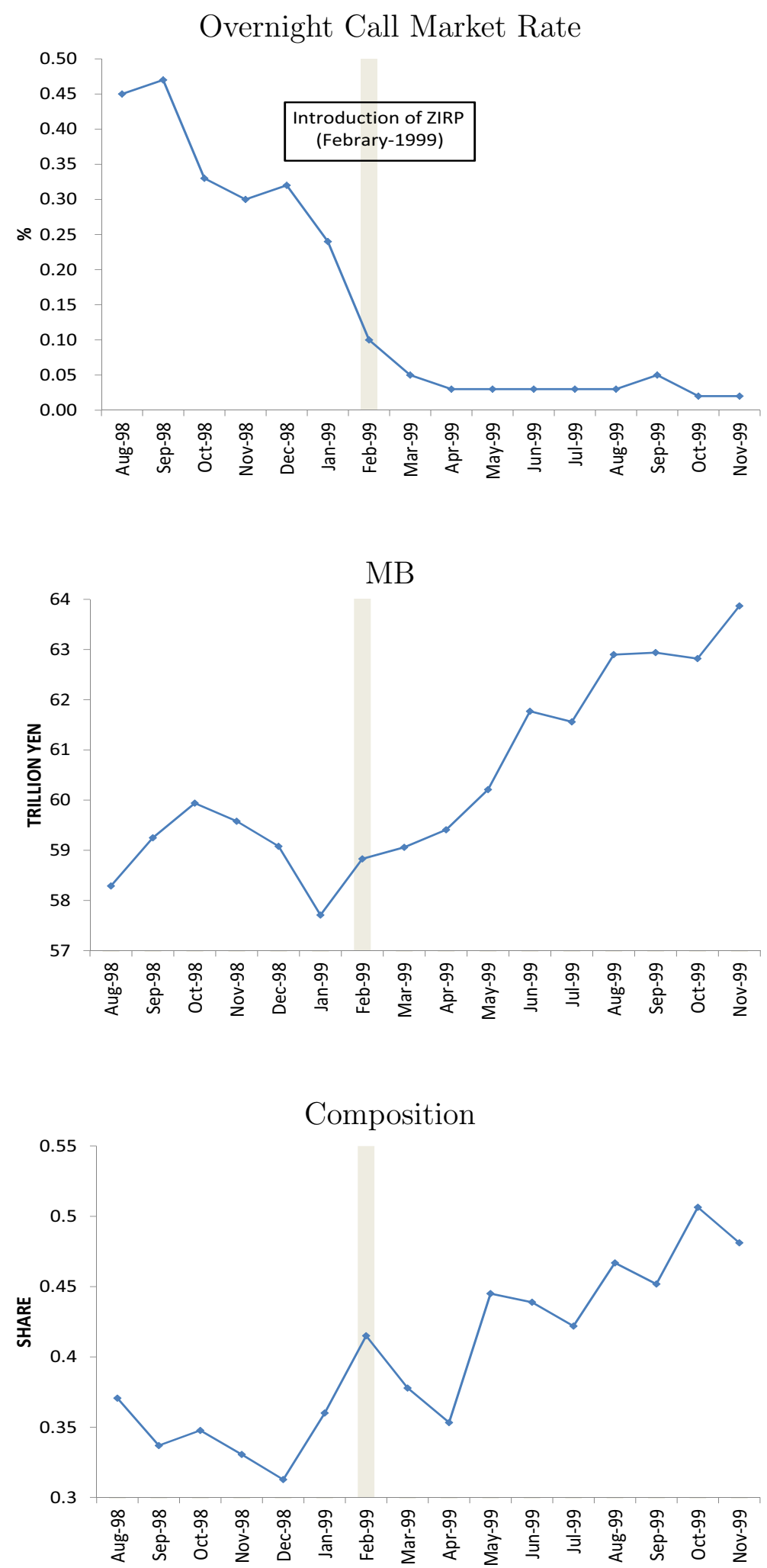
Figure 3: Monetary Policy Variables around the End of ZIRP and the Introduction of QEMP
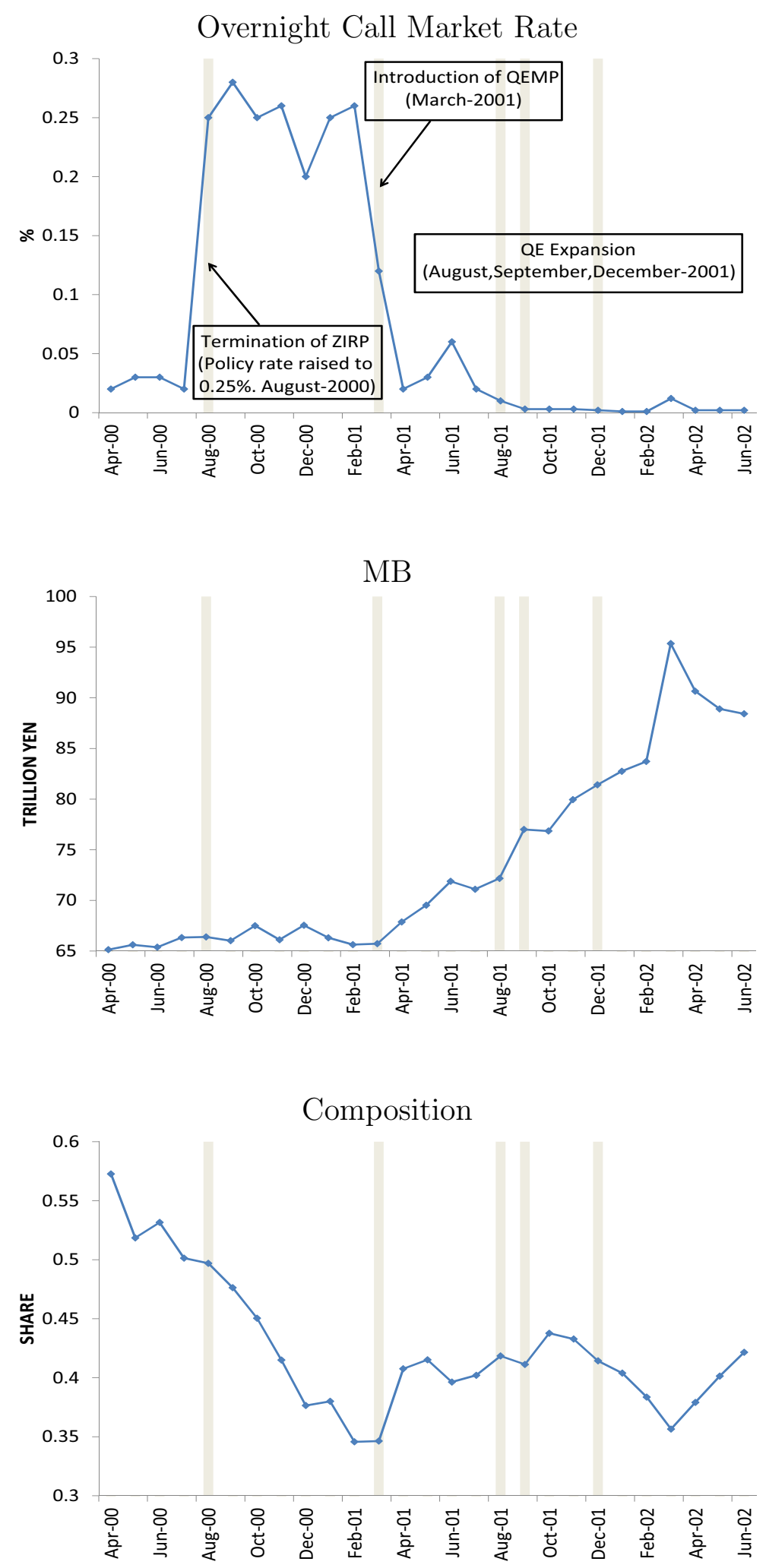
Figure 4: Monetary Policy Variables around the End of QEMP
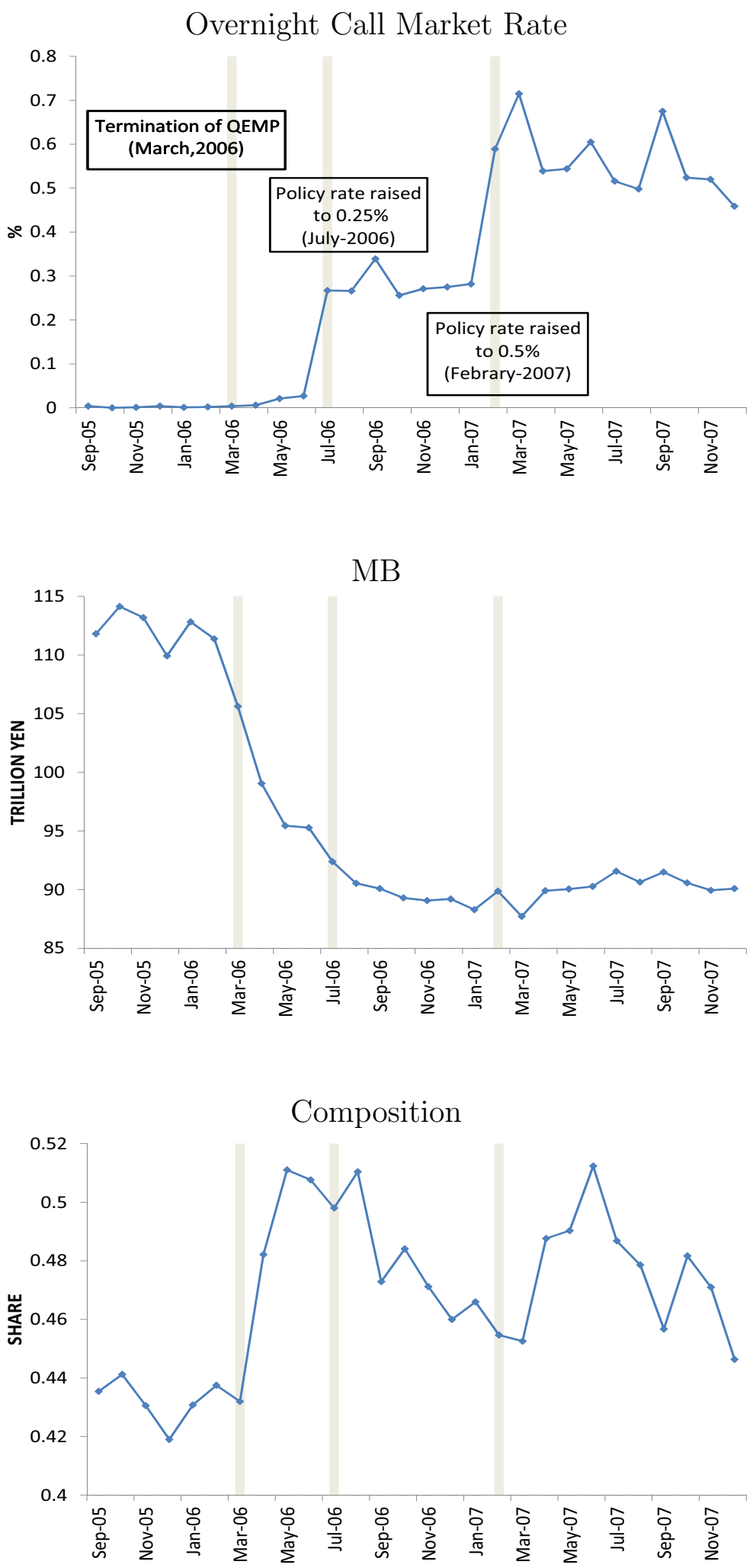
Figure 5: Monetary Policy Variables around the Introduction of QQE
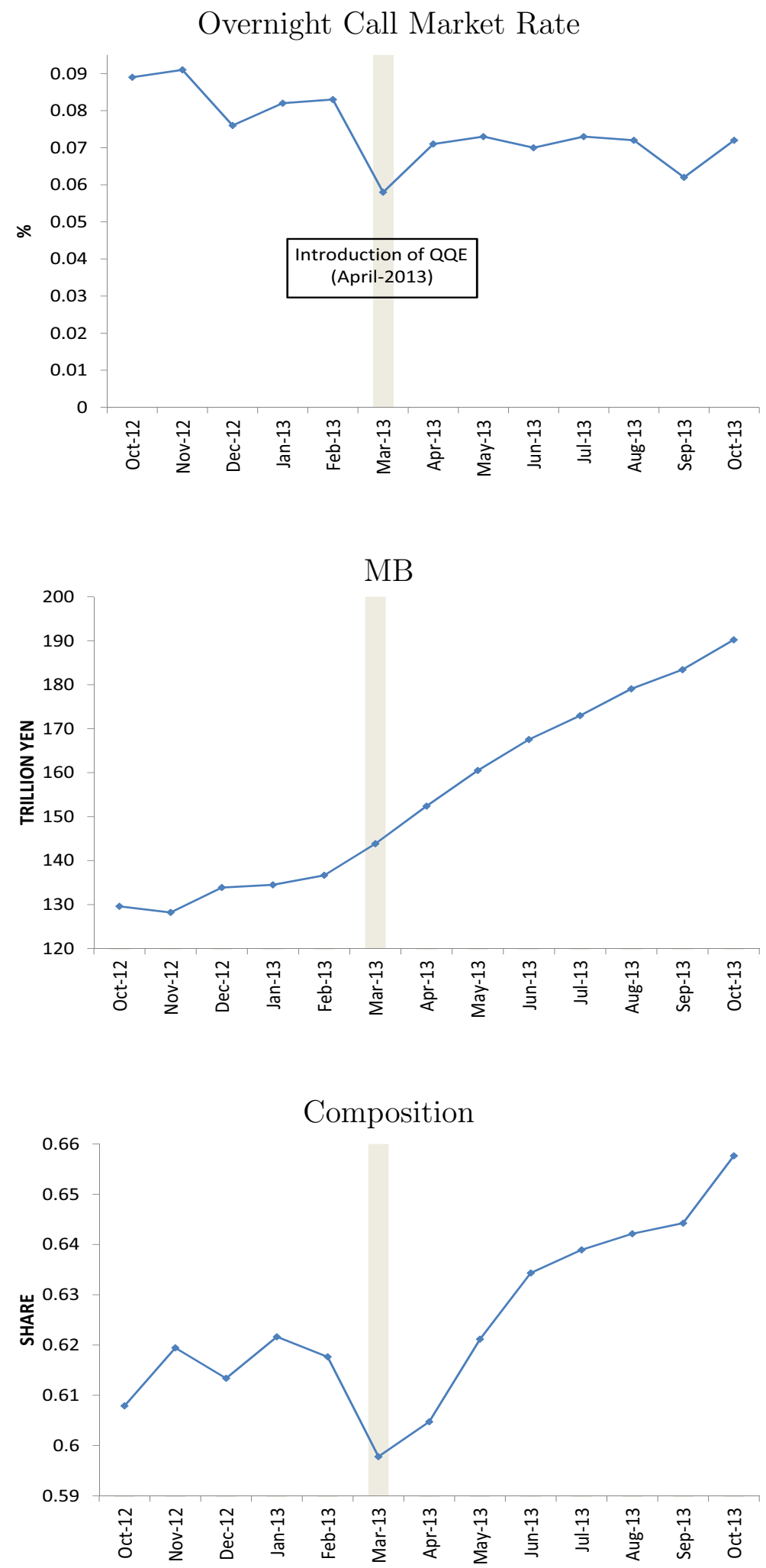


\section{Figure 6: Impulse Responses to the Quantitative Easing Shock}
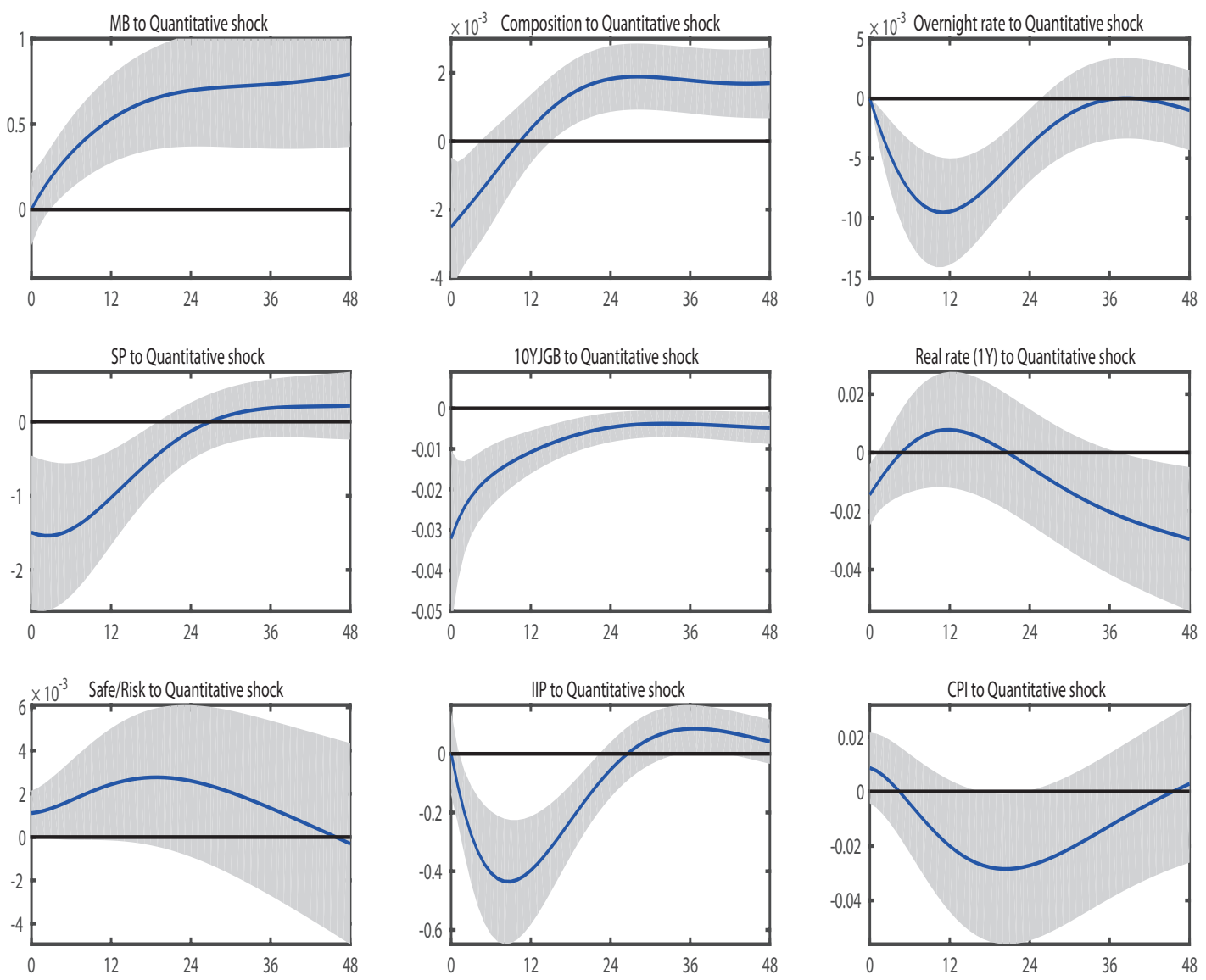

Notes: The solid lines represent the point estimates of the impulse responses to a quantitative monetary policy shock in the baseline VAR model. The shaded areas represent the \pm one standard error confidence band calculated by the bias-adjusted bootstrap method with 1000 replications. 


\section{Figure 7: Impulse Responses to the Qualitative Easing Shock}
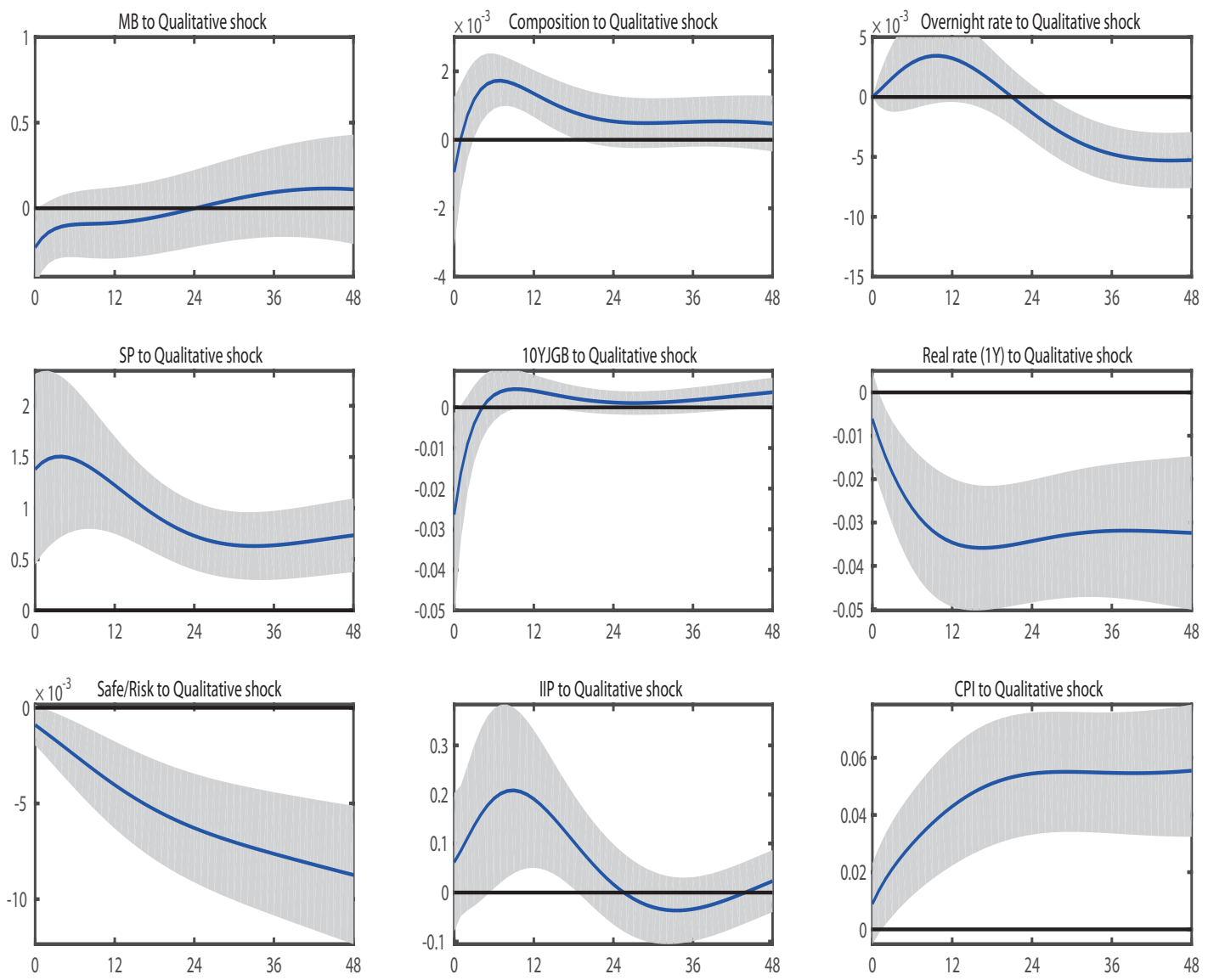

Notes: The solid lines represent the point estimates of the impulse responses to a qualitative monetary policy shock in the baseline VAR model. The shaded areas represent the \pm one standard error confidence band calculated by the bias-adjusted bootstrap method with 1000 replications. 


\section{Figure 8: Impulse Responses to the Conventional Monetary Policy Easing Shock}
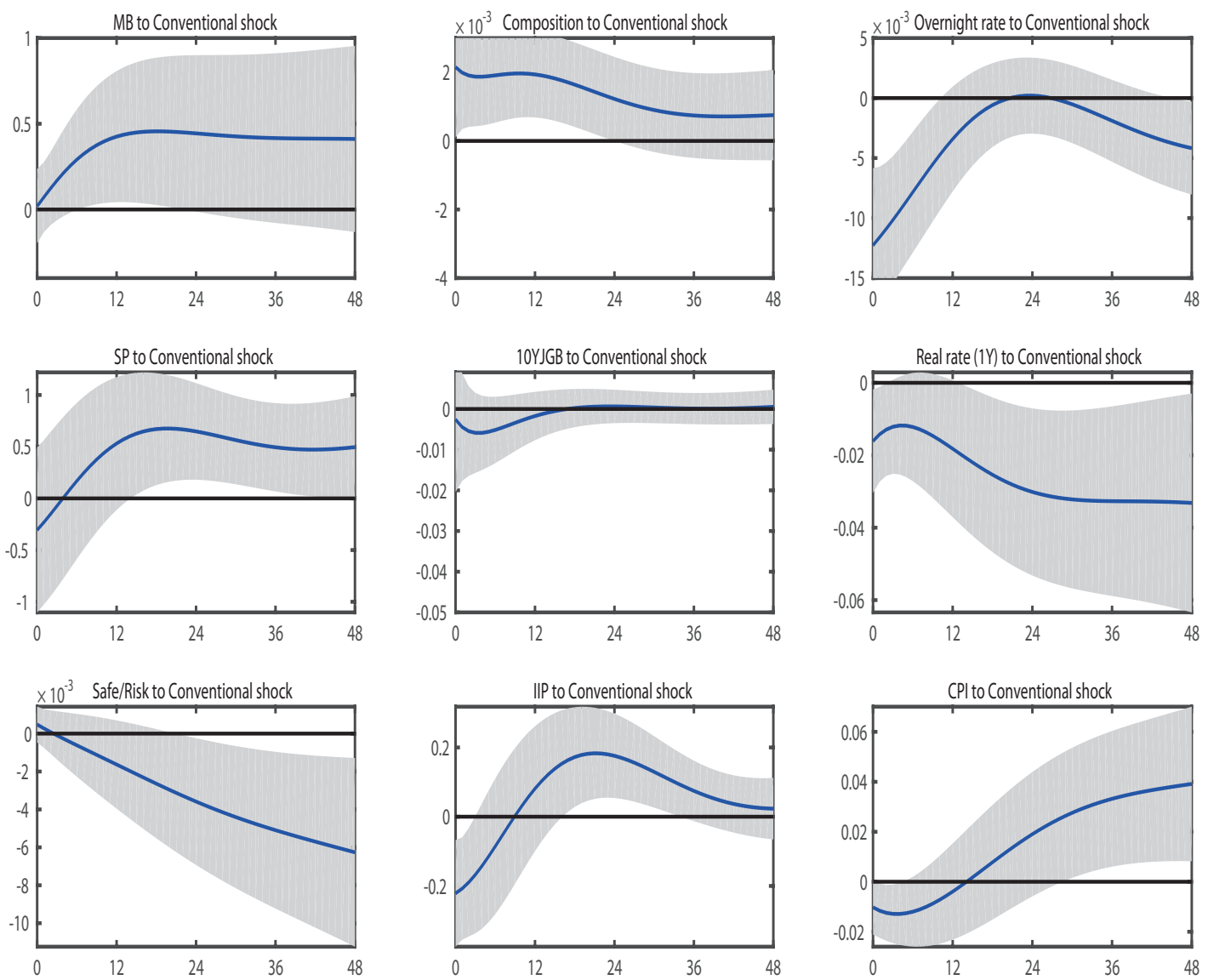

Notes: The solid lines represent the point estimates of the impulse responses to a conventional monetary policy shock in the baseline VAR model. The shaded areas represent the \pm one standard error confidence band calculated by the bias-adjusted bootstrap method with 1000 replications. 